\begin{abstract}
UNIVERSIDADE DE SÃO PAULO
FACULDADE DE MEDICINA DE RIBEIRÃO PRETO
\end{abstract}

CASSIA SENGER

Avaliação automatizada do desempenho de busca visual em pacientes com glaucoma primário de ângulo aberto

RIBEIRÃO PRETO 


\section{CASSIA SENGER}

\section{Avaliação automatizada do desempenho de busca visual em pacientes com glaucoma primário de ângulo aberto}

Tese apresentada à Faculdade de Medicina de Ribeirão Preto da Universidade de São Paulo para obtenção do Título de Doutor em Ciências.

Área de Concentração: Mecanismos Fisiopatológicos nos Sistemas Visual e AudioVestibular.

Orientador: Prof. Dr. Jayter Silva de Paula 
Autorizo a reprodução e divulgação total ou parcial deste trabalho, por qualquer meio convencional ou eletrônico, para fins de estudo e pesquisa, desde que citada a fonte.

\section{Catalogação da Publicação}

Preparada pela Biblioteca do Serviço de Biblioteca e Documentação

Faculdade de Medicina de Ribeirão Preto da Universidade de São Paulo

Senger, Cassia.

Avaliação automatizada do desempenho de busca visual em pacientes com glaucoma primário de ângulo aberto / Cassia Senger; orientador Jayter Silva de Paula. - Ribeirão Preto, 2017.

83f.; 12 il.

Tese (Doutorado) - Faculdade de Medicina de Ribeirão Preto da Universidade de São Paulo. Departamento de Oftalmologia, Otorrinolaringologia e Cirurgia de Cabeça e Pescoço. Área de concentração: Mecanismos Fisiopatológicos nos Sistemas Visual e Áudio-Vestibular.

1. Glaucoma primário de ângulo aberto; 2. Busca visual; 3. Defeito de campo visual; 4. Leitura; 5 . Movimento ocular; 6 . Perda visual perimétrica.

CDD 999.99 
FOLHA DE APROVAÇÃO

\section{Aluna: Cassia Senger}

Título: Avaliação automatizada do desempenho de busca visual em pacientes com glaucoma primário de ângulo aberto.

Tese apresentada à Faculdade de Medicina de Ribeirão Preto da Universidade de São Paulo para obtenção do Título de Doutor em Ciências.

Área de Concentração: Mecanismos Fisiopatológicos nos Sistemas Visual e AudioVestibular.

Aprovada em:

Prof. Dr.

Instituição:

Assinatura:

Prof. Dr.

Instituição:

Assinatura:

Prof. Dr.

Instituição:

Assinatura:

Prof. Dr.

Instituição:

Assinatura:

Prof. Dr.

Instituição:

Assinatura: 


\section{Dedicatória}

Ao meu marido Tom, à minha filha Júlia e aos meus pais, Roldão e Ana Lúcia, o meu amor e gratidão pelo incentivo e apoio recebidos ao longo da elaboração deste trabalho. 


\section{Agradecimentos}

Ao meu orientador Prof. Dr. Jayter Silva de Paula, pela atenção, paciência e pelo apoio durante todos os processos deste estudo, sendo um inspirador exemplo para meu aprimoramento científico, ético e profissional.

Ao Prof. Dr. André M. V. Messias, pelos ensinamentos, pelo apoio e pela ajuda na avaliação dos dados.

Ao Dr. Marcelo Jordão Lopes da Silva, que muito incentivou e contribuiu para o meu crescimento científico e intelectual.

À Dra. Luciana de Moraes Vicente, pelo apoio nessa jornada, pela presença ética e incentivadora na minha vida profissional e acadêmica.

À Faculdade de Medicina de Ribeirão Preto da Universidade de São Paulo, pela grande oportunidade de realização do Curso de Doutorado.

Ao Departamento de Oftalmologia, Otorrinolaringologia e Cirurgia de Cabeça e Pescoço da Faculdade de Medicina de Ribeirão Preto da Universidade de São Paulo. Em especial às funcionárias: Maria Cecília Onofre, por sua orientação, pelo apoio e processamento do material e Eliane Santos Damasceno, pela paciência, pelo apoio, pela cordialidade e confiança.

Aos funcionários do Ambulatório de Oftalmologia do Hospital das Clínicas da Faculdade de Medicina de Ribeirão Preto da Universidade de São Paulo, em especial às técnicas: Lucélia Albiéri, Elisete M. G. da Silva, Maria Helena dos R. Almeida e Leonice C. S. Rufino, pela cooperação, boa vontade e paciência durante a execução da pesquisa de campo deste estudo.

Aos colegas e amigos Túlio Reis e Paulo Puccinelli, pela cooperação e pelo auxílio na triagem e realização de exames dos participantes deste estudo.

Aos pacientes voluntários, sem eles não seria possível a realização deste estudo.

Ao espírito científico da eterna busca do conhecimento, aprimoramento e desenvolvimento humano. 
SENGER, C. Avaliação automatizada do desempenho de busca visual em pacientes com glaucoma primário de ângulo aberto. 2017. 83f. Tese (Doutorado) - Faculdade de Medicina de Ribeirão Preto, Universidade de São Paulo, Ribeirão Preto, 2017.

A busca visual é uma habilidade crítica para várias tarefas da vida diária e pode estar prejudicada em pacientes com deficiência visual. O objetivo deste estudo foi comparar a busca visual exploratória entre pacientes com glaucoma primário de ângulo aberto (GPAA) e controles saudáveis, avaliando a correlação espacial entre áreas com perdas localizadas na busca visual exploratória e os defeitos perimétricos, em pacientes com GPAA e com visão normal. Cinquenta e sete indivíduos com visão normal (acuidade visual corrigida melhor que 0.2 logMAR) diagnosticados (grupo GPAA, $n=29$ ) ou não (grupo CONTROL, $n=28$ ) com GPAA, realizaram um exame oftalmológico completo, incluindo perimetria visual (Humphrey -Fast 24.2) e uma tarefa exploratória de busca visual baseada em uma tela com dígitos. Um software personalizado quantificou o (s) tempo (s) gasto (s) até o encontro do número "4" em uma matriz aleatória de dígitos distribuídos em cinco áreas, em nove telas sequenciais do programa. Cinco áreas da tela de busca visual foram espacialmente correlacionadas com cinco setores do mapa total deviation (TD) da perimetria visual, após ajustes de ângulo e distância. A análise de covariância (ANCOVA) e testes de correlação foram utilizados para correlacionar parâmetros perimétricos e da busca visual exploratória, por meio de avaliação do tempo individual (gasto para encontrar cada dígito) e tempo total (gasto para completar a tarefa). Os pacientes com GPAA apresentaram pior sensibilidade perimétrica (MD) e de busca visual exploratória do que os controles (MD: $-8,02 \pm 7,88 \mathrm{~dB}$ vs $-1,43 \pm 1,50 \mathrm{~dB} ; \mathrm{p}<0,0001$ e tempo total: $106,42 \pm 59,64$ $s$ vs $52,75 \pm 19,07 \mathrm{~s} ; \mathrm{p}<0.0001)$. A sensibilidade do MD de ambos os grupos correlacionou-se significativamente com o tempo total (GPAA: $r=-0.45 ; p=0,01$ e CONTROL: $r=0,37 ; p=0,049)$. Os testes de ANCOVA mostraram uma correlação significativa entre a busca visual exploratória (tempo individual) e a acuidade visual $(P=0,006)$ e o diagnóstico de glaucoma $(p=0,005)$. $A$ sensibilidade média das áreas perimétricas periféricas do grupo GPAA mostrou correlação significativa com o tempo de busca individual nas áreas espaciais correspondentes, exceto na área periférica temporal superior $(r=-0,35, p=0,06)$. Os controles não mostraram correlação significativa para nenhuma dessas áreas perimétricas, exceto a área periférica temporal superior $(r=0,43, p=0,02)$. Com base em nossos resultados, regiões com pior desempenho na busca visual exploratória puderam ser correlacionadas às perdas periféricas localizadas dos pacientes com GPAA. Uma vez que foram estudados pacientes com acuidade visual normal, estes achados destacam a importância do uso de ferramentas de busca visual na avaliação do impacto das perdas perimétricas periféricas em atividades diárias de pacientes com glaucoma.

Palavras-chave: Glaucoma primário de ângulo aberto; Busca visual; Movimento ocular; Defeito perimétrico. 
Abstract 
SENGER, C. Automated assessment of visual search performance in patients with open angle primary glaucoma. 2017. 83f. Thesis (Doctoral). Ribeirão Preto Medical School, University of São Paulo, Ribeirão Preto, 2017.

Visual search is a critical skill for several daily tasks and may be declined in patients with impaired vision. The objectives of this study were to compare the exploratory visual search performance (EVSP) between patients with primary open-angle glaucoma (POAG) and healthy controls, and evaluate the spatial correlation between localized decreases in the EVSP and areas of visual field (VF) loss in normally-sighted patients POAG. Fifty-seven normal vision subjects (best corrected visual acuity better than 0.2 logMAR) diagnosed (POAG group; $n=29$ ) or not (CONTROL group; $n=28$ ) with POAG yielded a complete comprehensive ophthalmological examination, including Humphrey VF tests (SITA-Fast 24.2), and an exploratory visual search digit-based task. A custom software quantified the time (s) spent until patients found the number " 4 " on a random array of digits distributed in five areas on nine sequential screens. Each area was spatially matched with five sectors of the total deviation map from VF, after angle and distance adjustments. Covariance (ANCOVA) and correlation tests were used for correlating VF parameters and EVSP, evaluated through individual time (spent for finding each digit) and total time (spent for completing the task). POAG patients presented worse VF mean deviation (MD) sensitivity and EVSP than controls (MD: $-8.02 \pm 7.88 \mathrm{~dB}$ vs $-1.43 \pm 1.50 \mathrm{~dB} ; \mathrm{p}<0.0001$, and total time: $106.42 \pm 59.64 \mathrm{~s}$ vs $52.75 \pm 19.07 \mathrm{~s} ; \mathrm{p}<0.0001)$. MD sensitivity of both groups significantly correlated with total time (POAG: $r=-0.45 ; p=0.01$ and CONTROL: $r=0.37 ; p=0.049$ ). ANCOVA tests showed a significant correlation between EVSP (individual time) and both visual acuity $(p=0.006)$ and glaucoma diagnosis $(p=0.005)$. The mean sensitivity of the peripheral VF areas of the POAG group showed significant correlation with the individual search time in the corresponding spatial areas, except in the peripheral temporal superior area $(r=-0.35, p=0.06)$. Controls did not show a significant correlation for any of those VF areas, except the peripheral temporal superior area $(r=0.43, p=0.02)$. Based on our results, worse EVSP can be attributable to localized losses in the peripheral VF areas in patients with POAG. Since only normally sighted patients were studied, these findings highlight the importance of using visual search tools to evaluate the impact of peripheral VF loss in daily activities of glaucoma patients, such as driving.

Keywords: Primary open angle glaucoma; Visual search; Eye movement; Visual field defects. 
Lista de Figuras 
Figura 1: Prevalência do GPAA na Europa, África e Ásia, por idade, com base nos dados apresentados por Quigley et al. (1996) (19) ............22

Figura 2: Retinografia do nervo óptico. (A) normal; (B) glaucomatoso 23

Figura 3: Exemplos de impressos da perimetria visual obtidos pelo perímetro Humphrey, mostrando a progressão da perda visual relacionada ao glaucoma, observada com intervalos de dois anos. Nota-se piora da sensibilidade nas áreas nasais e central no sentido da esquerda para a direita, (A) imagem inicial, (B) após dois anos, (C) após quatro anos....

Figura 4: Fotografia da tela com o programa Four em execução, com os dígitos aleatoriamente apresentados

Figura 5: Esquema demonstrando as dimensões entre o olho examinado e a tela usada para o teste de busca visual. À esquerda, a tela com dimensões de $70 \times 40 \mathrm{~cm}$. À direita, o indivíduo com correção para perto, olho direito ocluído, olho esquerdo centralizado na tela, a $62 \mathrm{~cm}$ de distância

Figura 6: Fotografia de uma tela em execução do programa Four, com sujeito em exame.

Figura 7: Foto de um paciente do grupo GPAA em exame, sentado, com a face posicionada na queixeira, olho direito ocluído e olho esquerdo centralizado na tela

Figura 8: Desenho esquemático demonstrando as relações utilizadas para cálculos de correspondência em termos de amplitude de campo de visão vertical e horizontal na tela usada para busca visual, considerando a distância fixa entre o olho examinado e o centro da tela.

Figura 9: Divisão da tela do exame de busca visual, que abrange 36 graus verticalmente e 60 graus horizontalmente do campo visual central. As cinco áreas são correspondentes com as áreas perimétricas

Figura 10: Gabarito para análise de confrontação entre a sensibilidade perimétrica $x$ desempenho de busca na tela do exame de busca visual padronizada

Figura 11: Representação esquemática do exame de busca visual, com a localização de cada alvo apresentado e sua ordenação temporal 
quanto à sua identificação pelo participante, ao longo do exame (através das cores e tamanhos das esferas)

Figura 12: Montagem demonstrando os gráficos do exame de PV de um paciente do grupo GPAA e a distribuição espacial dos tempos individuais de busca dos estímulos visuais em diversas áreas da tela do programa Four. Acima, à esquerda: o gráfico pattern deviation; acima, à direita: o gráfico perimétrico em escala de cinza; em baixo, à esquerda: o gráfico total deviation; em baixo, à direita: gráfico demonstrando o tempo de busca de cada alvo nas nove telas, estando o diâmetro e a cor dos círculos representados de modo diretamente proporcional ao tempo gasto para determinação de cada estímulo. Notar boa correlação entre os maiores círculos no gráfico de busca visual e áreas de escotomas predominando no quadrante nasal superior da PV, ultrapassando discretamente as linhas horizontais e verticais 
Lista de Tabelas 
Tabela 1 - Expectativa do número de pessoas com Glaucoma no mundo, em 2020 , com base nos resultados apresentados por Quigley et al. (2006) (18)

Tabela 2 - Dados demográficos, condições gerais e características clínicas dos sujeitos estudados

Tabela 3 - Valores médios de sensibilidade globais e nas áreas estudadas da perimetria visual, por grupo.

Tabela 4 - Distribuição dos valores médios de tempo total e individual global e nas áreas estudadas para Busca Visual, por grupo

Tabela 5 - Correlações entre os resultados dos tempos individual global de busca visual, MD, AVCC e idade

Tabela 6 - Análise de covariância para correlação do tempo individual global de busca visual com o MD, AVCC, idade e grupo de estudo

Tabela 7 - Correlações entre os resultados de tempo individual de busca visual e parâmetros da PV, globais e organizados por áreas espaciais correspondentes. 
Lista de Abreviaturas 
○ $\quad$ Grau

$\mu \mathrm{m}-\quad$ Micras

AVCC- $\quad$ Melhor acuidade visual corrigida

CEN- Região central da tela

CGR- Células ganglionares da retina

dB- Decibéis

DMRI- Degeneração macular relacionada à idade

DO- Disco óptico

E/D- Escavação vertical/Diâmetro disco óptico

GHT- Testes de glaucoma no hemicampo, do inglês, Glaucoma Hemifield Test

GPA- $\quad$ Glaucoma primário de ângulo aberto

HCFMRP-USP- Hospital das Clínicas da Faculdade de Medicina de Ribeirão Preto da Universidade de São Paulo

logMAR- $\quad$ Escala linear logarítmica de perda de acuidade visual

MD- Desvio médio de sensibilidade, do inglês, Mean Deviation

M- Numeração da linha, de forma crescente na tabela de Snellen

mmHg- Milímetros de mercúrio

OCT- $\quad$ Tomografia de coerência óptica

OMS- $\quad$ Organização Mundial de Saúde

p- $\quad$ Probabilidade

PC- Computador pessoal

PIN- Região nasal periférica inferior da tela

PIO- Pressão intraocular

PIT- Região temporal periférica inferior da tela 
POAG- do inglês, Primary Open-angle Glaucoma

PSD- $\quad$ Desvio padrão, do inglês, Pattern Stand Deviation

PSN- Região nasal periférica superior da tela

PST- Região temporal periférica superior da tela

PV- $\quad$ Perimetria visual

r- $\quad$ Coeficiente de correlação

RNFL- $\quad$ Camada de fibras nervosas da retina

s- $\quad$ Segundos

SITA- Algoritmo de limiar interativo sueco - do inglês Swedish interactive threshold algorithm

tABS- $\quad$ Tempo absoluto (tempo de exame)

TCLE- $\quad$ Termo de Consentimento Livre e Esclarecido

TD- Desvio total, do inglês, Total Deviation

TD CEN- Desvio total da área central

TD PIN- Desvio total da área nasal periférica inferior

TD PIT- Desvio total da área temporal periférica inferior

TD PSN- Desvio total da área nasal periférica superior

TD PST- Desvio total da área temporal periférica superior

$\operatorname{tg} \partial-\quad$ Tangente do ângulo alpha (vertical)

tgß- $\quad$ Tangente do ângulo beta (horizontal)

TIG- Tempo Individual Global

tIND- $\quad$ Tempo individual (tempo de cada estímulo) 


\section{SUMÁRIO}

1. INTRODUÇÃO

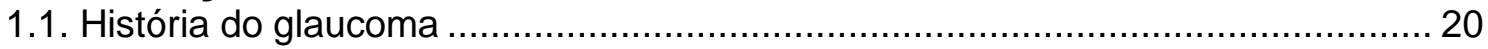

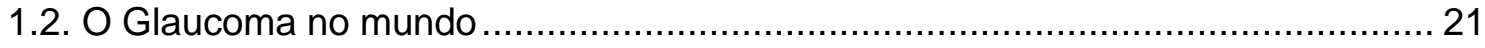

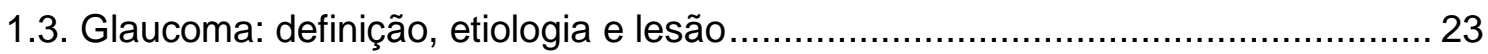

1.4. Glaucoma primário de ângulo aberto (GPAA): definição, diagnóstico, seguimento

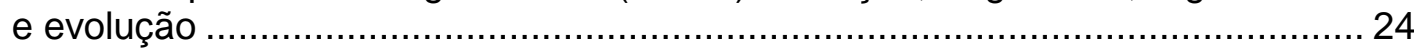

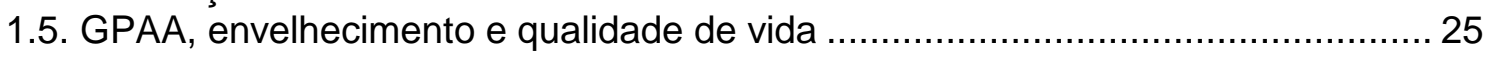

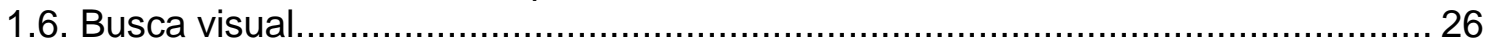

1.7. Glaucoma e o desempenho na busca visual .................................................. 29

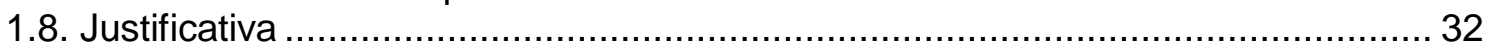

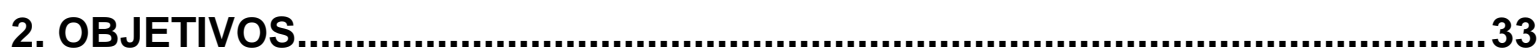

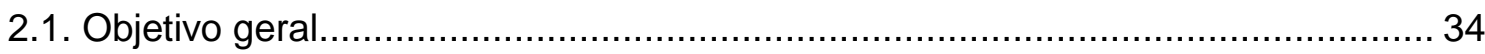

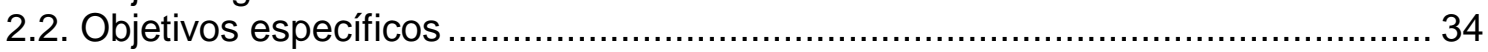

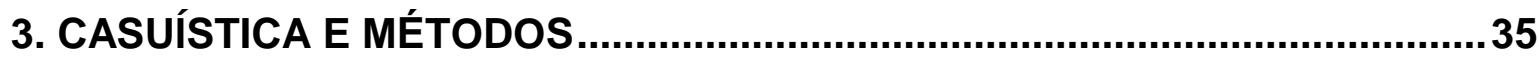

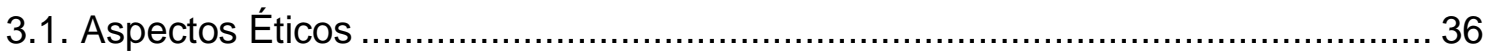

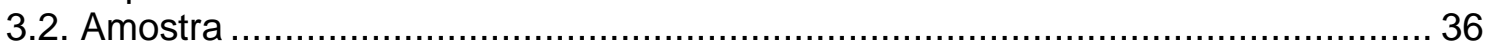

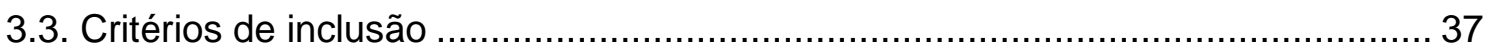

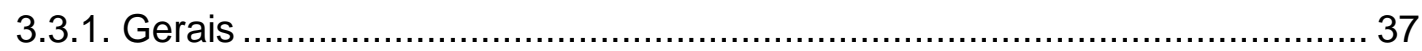

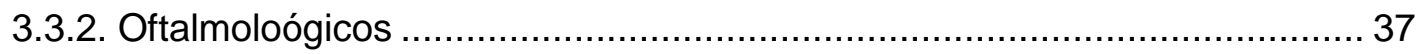

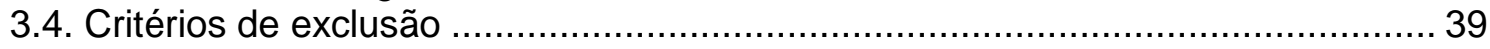

3.5. Protocolos de exames .......................................................................... 39

3.5.1 Perimetria visual computadorizada ……………………………...... 39

3.5.2. Busca visual (Teste de estímulos visuais em plataforma computacional) ... 40

3.6. Análise dos resultados ...................................................................................... 43

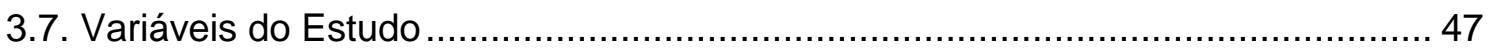

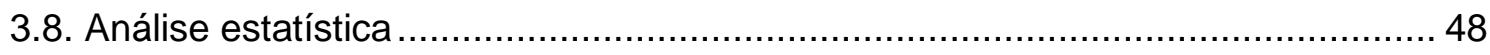

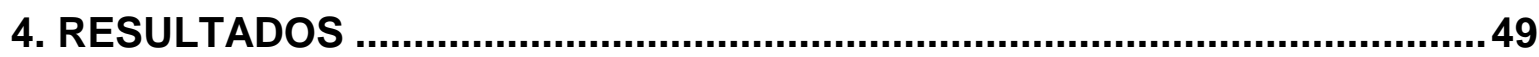

4.1. Dados demográficos e clínicos ………………............................................. 50

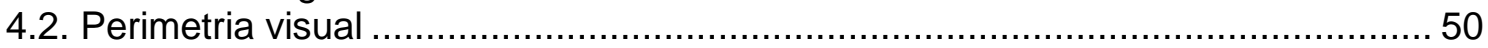

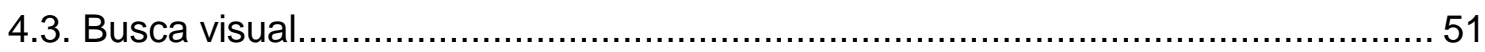

4.4. Correlações entre busca visual, idade, sexo, acuidade visual e perimetria visual .. 52

5. DISCUSSÃO

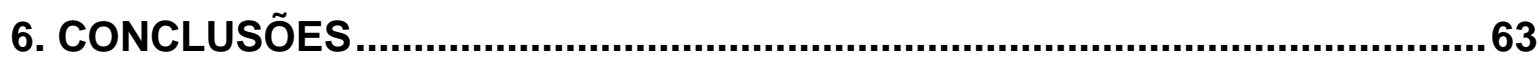

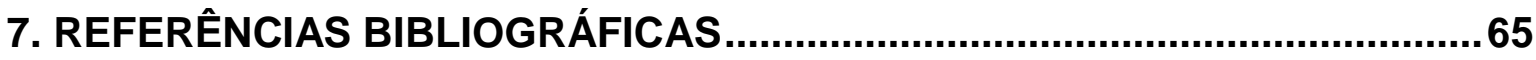

8. ANEXOS

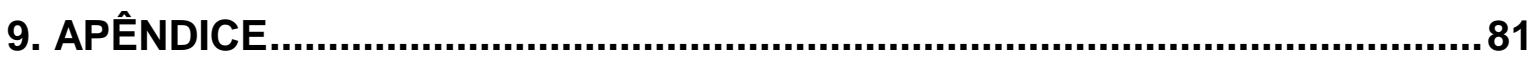




\section{1- Introdução}




\subsection{História do glaucoma}

O termo glaucoma deriva do grego "glaukos" da antiguidade. Acredita-se que se referia a um grupo de patologias oculares que levavam à cegueira e davam ao olho um brilho esverdeado (1). Numa placa de argila da antiga Mesopotâmia há referência a crianças cegas, com olhos salientes e anormalmente grandes (que provavelmente seriam olhos buftálmicos do glaucoma congênito) (2). Hipócrates (3), no seu aforismo 31 da III secção, faz referência ao "glaucoma", como uma doença de idosos. Na escola de Alexandria (século III - II a.C.), o glaucoma era considerado uma doença incurável e que causava alteração da cor e do brilho da pupila (4). Na Idade Média, acreditava-se que o glaucoma era como uma catarata incurável. Somente a partir do século XVIII reconheceu-se que a alteração da cor pupilar não tinha sempre a mesma causa, colocando a catarata e o glaucoma como patologias distintas, cuja confirmação ocorreu por uma rudimentar cirurgia de catarata extracapsular em 1748 (5). A primeira descrição categórica do glaucoma foi feita pelo cirurgião inglês Richard Banister, o primeiro especialista em oftalmologia, considerado o pai da oftalmologia britânica, após publicar obras sobre doenças oculares como o tratado Banister's Breviary of the Eye, em 1622 (6).

Em 1722, Saint-Yves (7) relatou a perda perimétrica, dando início ao maior conhecimento dessa afecção ao longo das décadas seguintes que, com 0 desenvolvimento técnico no século XIX, permitiu descrever e conhecer cada vez melhor a doença. Em 1854, von Graefe (8), descrevendo o disco óptico (DO) no glaucoma, desenhou seu aspecto oftalmoscópico, descreveu a escavação e considerou que o aumento da pressão intraocular (PIO) não era apenas um sintoma, mas sim, a própria existência da doença.

No início do século $X X$, já havia boa compreensão da relação entre o aumento da PIO e a gênese da escavação glaucomatosa do nervo óptico, e que esta não era apenas devido ao efeito mecânico do aumento da PIO, mas também resultante de alterações circulatórias e metabólicas (9).

Von Graefe, Doders e Schnabel $(8,10)$ foram fundadores da oftalmologia científica. Na década de 1920, iniciaram a abordagem e a discussão sobre os 
mecanismos do glaucoma de ângulo aberto e fechado e glaucoma secundário. Curran (11) e Seidel (12) identificaram o bloqueio pupilar. Barkan (13) dividiu o glaucoma em ângulo aberto e fechado por meio da descrição da posição do ângulo camerular.

O contínuo progresso no conhecimento do glaucoma foi imprescindível para o desenvolvimento de meios diagnósticos, tratamentos clínicos e técnicas cirúrgicas, tão importantes nos dias de hoje. O glaucoma conta com vasta e incansável alma científica, e este estudo almeja ser uma centelha nesse universo evolutivo, que vê no controle dessa grave doença, um passo em prol da melhoria da qualidade de vida humana.

\subsection{Glaucoma no mundo}

O glaucoma é uma das principais causas mundiais de deficiência visual (14). Segundo a Organização Mundial de Saúde (OMS), é a segunda causa de cegueira e a primeira causa de cegueira irreversível no mundo. Acomete até 4\% dos adultos com idade acima de 45 anos. Estima-se que haja cerca de 70 milhões de pessoas portadoras de glaucoma (15-18) e que até um terço desses não tem sua doença diagnosticada até o momento (19) (Tabela 1). Acredita-se que cerca de oito milhões de indivíduos sejam cegos bilateralmente devido ao glaucoma $(18,19)$. O glaucoma é responsável pelo impacto social, médico e financeiro cada vez mais significativo. Sua prevalência varia segundo localização, raça, idade e características socioeconômicas da população estudada $(20,21)$. O risco estimado de cegueira unilateral pelo glaucoma, ao longo de 20 anos de doença, chega a $54 \%$ e de cegueira bilateral, a $22 \%$ (22). Na população de caucasianos com glaucoma, a prevalência de cegueira bilateral está entre 2,5\% (23) e 7,3\% (24) e entre afrodescendentes estima-se que seja superior a $7,5 \%(25,26)$ (Figura 1). 
Tabela 1 - Expectativa do número de pessoas com glaucoma no mundo, em 2020, com base nos resultados apresentados por Quigley e Broman (2006) (18).

\begin{tabular}{lcc}
\hline Região mundial & Portadores de Glaucoma & Porcentagem da população $\mathbf{4 0}$ anos \\
\hline China & $21,824,015$ & $3,05 \%$ \\
Índia & $16,088,243$ & $2,64 \%$ \\
Europa & $13,971,113$ & $2,40 \%$ \\
África & $8,359,451$ & $4,39 \%$ \\
América Latina & $8,011,575$ & $3,60 \%$ \\
Japão & $3,084,669$ & $3,96 \%$ \\
Mundo & $79,640,184$ & $2,86 \%$ \\
\hline
\end{tabular}

Fonte: Adaptado de Quigley e Broman (2006, p. 265) (18)

Figura1 - Prevalência do GPAA na Europa, África e Ásia, por idade, com base nos dados apresentados por Quigley (1996) (20)

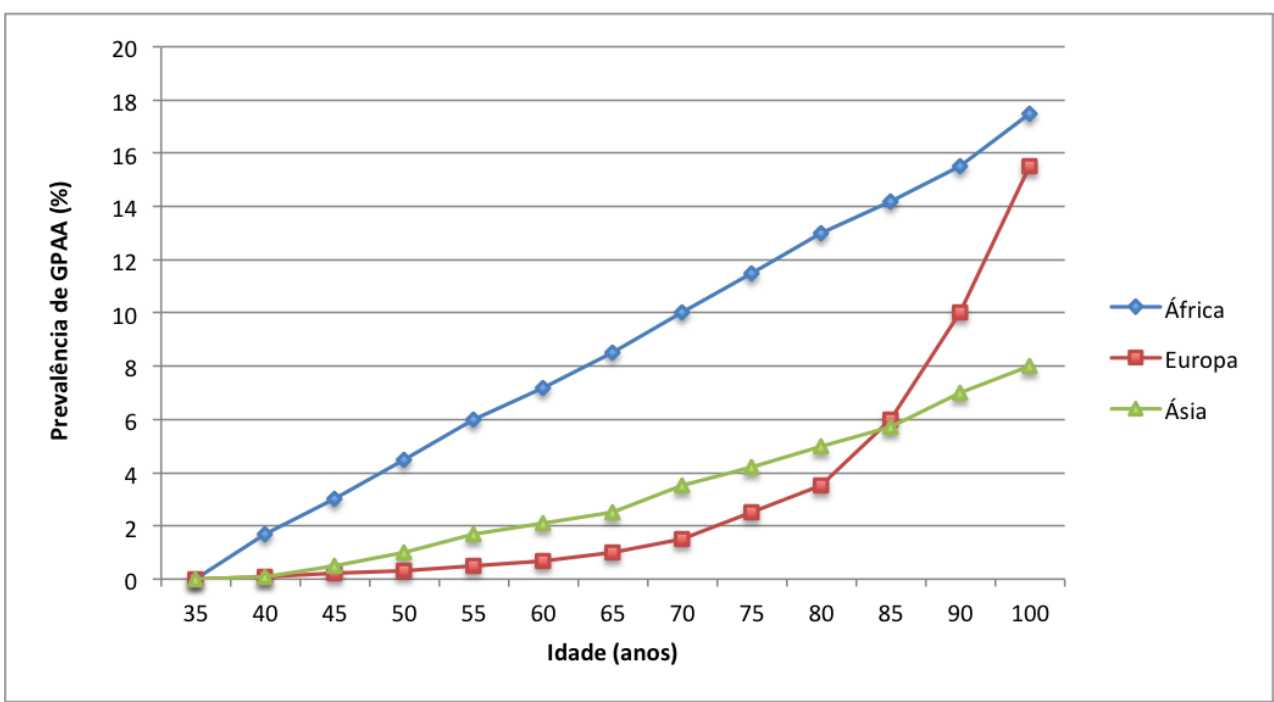

Fonte: Adaptado de Quigley (1996, p. 390) (19). 


\subsection{Glaucoma: definição, etiologia e lesão}

O glaucoma é uma neuropatia óptica progressiva, de etiologia multifatorial e complexa, incluindo o envolvimento de vários genes e fatores ambientais (18,19,27-29). Tem como importante fator de risco, a idade $(19,27,30)$, porém o mais significativo deles é o aumento da PIO; considerado, em muitos casos, como causa das lesões (27,31-33). O estágio da doença, a idade de início, o inadequado controle da PIO e a progressão da lesão durante o tratamento são fatores de risco para a cegueira no glaucoma (28,34-36). Essa afecção não é uma entidade única, mas um conjunto heterogêneo de doenças com mecanismos patológicos distintos que causam o aumento da escavação da cabeça do nervo óptico decorrente da perda das células ganglionares da retina (CGR) e seus axônios $(18,27,28)$. Assim, com a perda das CGR ocorrem as alterações estruturais do DO (Figura 2) e, como consequência, mudanças correlacionadas na perimetria visual (PV) (Figura 3).

Figura 2 - Retinografia do nervo óptico. (A) normal; (B) glaucomatoso.

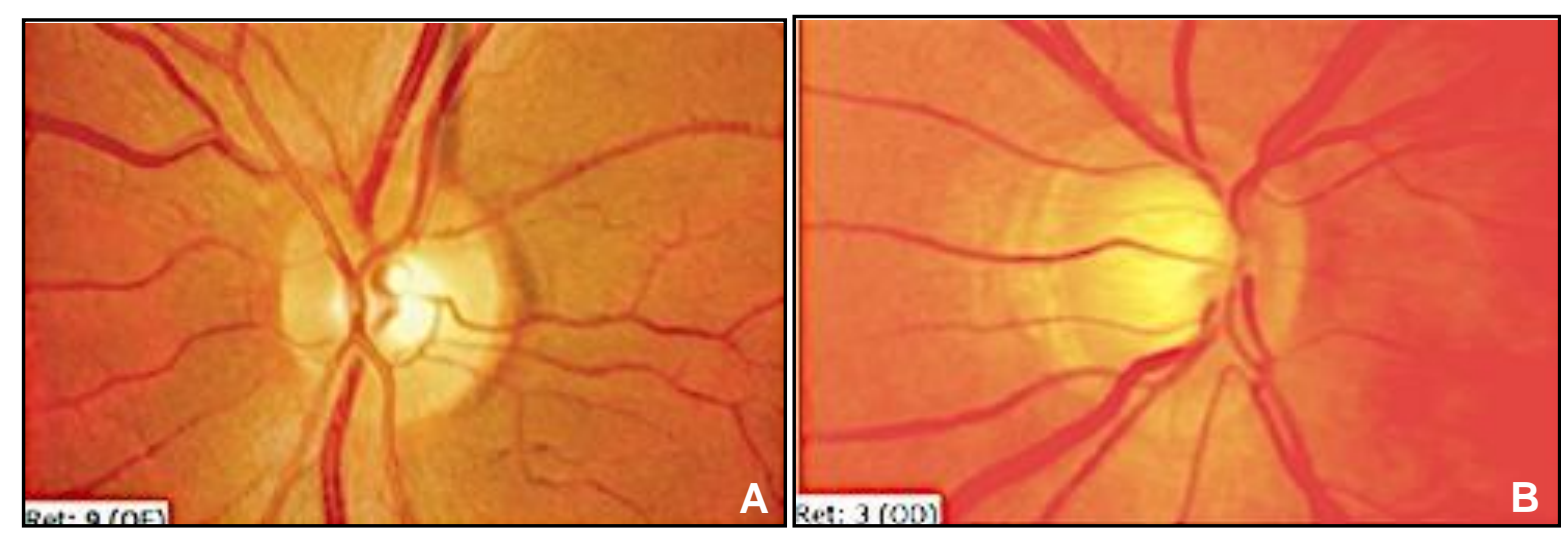


Figura 3 - Exemplos de impressos da perimetria visual obtidos pelo perímetro Humphrey, mostrando a progressão da perda visual relacionada ao glaucoma, observada com intervalos de dois anos. Nota-se piora da sensibilidade nas áreas nasais e central no sentido da esquerda para a direita. (A) imagem inicial, (B) após dois anos, (C) após quatro anos.

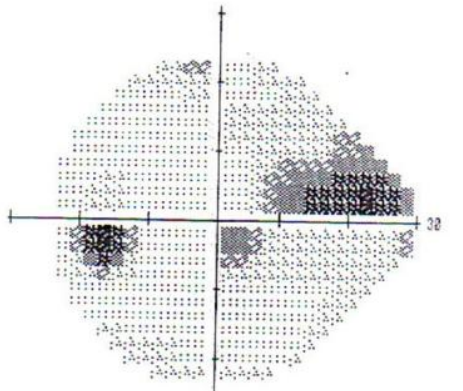

A

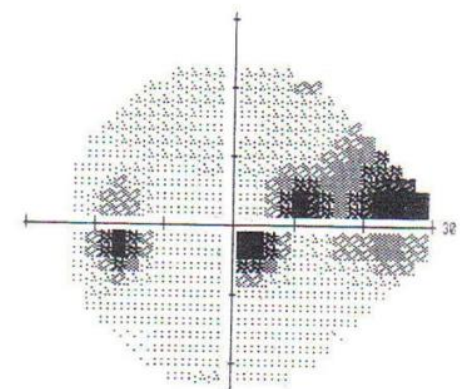

B

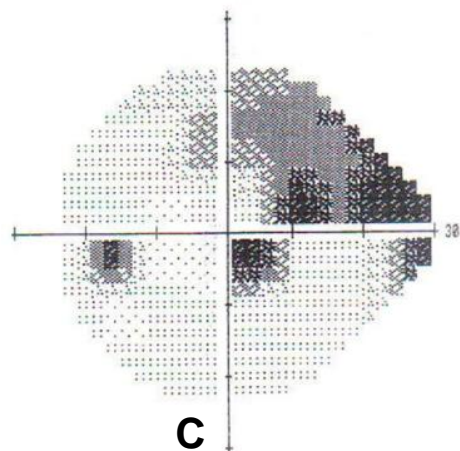

C

\subsection{Glaucoma primário de ângulo aberto (GPAA): definição, diagnóstico, seguimento e evolução}

O GPAA é a forma de glaucoma mais comum. Sua prevalência aumenta com a idade e varia entre $1,1 \%$ e $2,1 \%$ em indivíduos adultos caucasianos $(23,37)$, sendo de três a quatro vezes maior em afrodescendentes $(25,38)$. É uma neuropatia óptica crônica, idiopática, progressiva e irreversível, com dano estrutural característico do DO (dado pela lesão das CGR).

O diagnóstico, tratamento e seguimento do GPAA se baseiam em quatro fatores: na PIO, no ângulo da câmara anterior, na PV e na evidência de dano estrutural do DO (28,39-41), que devem ser analisados e seguidos periodicamente para o estabelecimento de propostas terapêuticas adequadas. $O$ exame da cabeça do nervo óptico define a presença do glaucoma; a gonioscopia indica o tipo do glaucoma, sendo que a anamnese, o exame físico, a acuidade visual e a PV revelam o quanto a doença está afetando o paciente $(28,42,43)$. Os exames perimétricos são largamente utilizados para o diagnóstico e seguimento do glaucoma e permitem que por meio de dispositivos computadorizados, se faça uma avaliação mais sensível e refinada da perda visual. Em geral, um defeito perimétrico é perceptível somente após perda de aproximadamente $40 \%$ das CGR $(28,29,44,45)$. 
As perdas perimétricas iniciais são descritas como perdas periféricas, mas muitas vezes não são específicas. Em geral, a perda visual progressiva no glaucoma se dá pelo desenvolvimento de duplo escotoma arqueado, coalescendo da região nasal até o meridiano temporal, podendo se estender aos limites periféricos de todas as áreas, levando à cegueira $(46,47)$. Dessa forma, escotomas arqueados e degraus nasais são os exemplos mais ilustrativos da perda neuronal na doença $(28,48)$. A evolução gera defeitos do tipo contração concêntrica e aumento da mancha cega (mais raramente), que revelam comprometimento difuso da camada de fibras nervosas da retina (RNFL).

Além dos defeitos perimétricos e de visão central, outras alterações na função visual podem estar presentes no glaucoma. Pacientes que apresentam glaucoma avançado têm menor sensibilidade ao brilho, após adaptação ao escuro, o que sugere que os fotorreceptores podem estar também lesados nessa doença (49). Sensibilidade reduzida a cores também é descrita em pacientes com glaucoma (50), bem como diminuição da sensibilidade ao contraste (51), sinais que refletem a evolução do dano celular (49).

\subsection{GPAA, envelhecimento e qualidade de vida}

O glaucoma afeta a visão de seus portadores progressivamente, levando ao comprometimento do desempenho profissional, de sua inserção social e pode prejudicar as atividades da vida cotidiana, com significativo impacto sobre o bem estar físico, emocional e mental do paciente $(39,52,53)$.

Idosos, em geral, apresentam maior dificuldade nas situações do cotidiano, pois convivem com as limitações e alterações inerentes ao envelhecimento corporal como um todo. A perda neuronal global, em geral, se acelera naturalmente com o passar da idade e está presente fisiologicamente após os 70 anos de idade (54). Quando na presença de doenças crônicas degenerativas, o impacto se torna ainda maior.

Sendo uma doença degenerativa, as perdas celulares no glaucoma estão associadas a um processo progressivo de aceleração da apoptose, levando à perda neuronal (primordialmente das CGR) e ao déficit funcional. Seu caráter 
neurodegenerativo se assemelha ao observado em outras doenças do sistema nervoso central, como a Doença de Alzheimer e o Parkinson (55). Com a perda de CGR, ocorrem as alterações irreversíveis na função visual. O doente tem, primeiramente, a sua sensibilidade visual reduzida; em seguida, há perda visual periférica e por último, o acometimento da visão central $(19,56,57)$.

Alguns autores estudaram a interação da função visual na vida das pessoas e as suas necessidades, pela capacidade de busca e discriminação visual e o uso simultâneo da visão foveal e periférica em afazeres cotidianos. Segundo a análise das respostas dos idosos, frente às questões relacionadas à velocidade e sensação de segurança ao executar tarefas associadas à função visual, em comparação ao seu próprio desempenho na idade entre 30 e 50 anos, houve, no grupo glaucomatoso, o frequente relato de diminuição significativa da capacidade individual (52,58-60). As tarefas pesquisadas foram: descer degraus, ler e identificar sinais e placas de informações, caminhar sozinho à noite, dirigir à noite, velocidade de leitura, tempo de observação até o reconhecimento de um objeto de busca, principalmente $(21,47,52,61)$. De maneira interessante, observou-se a necessidade de mudanças nos hábitos e passatempos, provavelmente devido à perda de qualidade visual $(49,52,61)$. Os resultados apontam para a necessidade de mais estudos com a população idosa para confirmação e compreensão desses achados.

Avaliar a qualidade de vida e as deficiências visuais no glaucoma é preocupação constante na literatura científica. Estudos baseados no desempenho desses pacientes podem oferecer método adicional para determinar o real impacto da doença na qualidade de vida dos pacientes $(39,52,58,61)$.

\subsection{Busca visual}

A busca visual pode ser definida como a capacidade de olhar rapidamente em busca de um alvo, isto é, realizar um movimento ocular sacádico para localizar um objeto de interesse no ambiente e direcioná-lo na fóvea para que possa ser identificado e reconhecido (62). Essa capacidade compreende, principalmente, a coordenação de sacádicos e determina o desempenho de busca. Tem sido 
frequentemente avaliada, usando a designação geral de desempenho de busca visual exploratória (60,63-65). Vários autores relataram que os movimentos oculares fixadores são caracterizados por uma sequência de derivações lentas e microsacadas (micro movimentos) rápidas, semelhantes a um padrão nistagmoide, denominados de sacádicos (66-72). Steinman et al. (1973) (69) relataram ambos os tipos de movimento em todos os sujeitos centralmente fixadores, enquanto Whittaker, Budd e Cummings (1988) (73) referiram sua ocorrência como "idiossincrática de sujeito a sujeito", sendo que todos os seus sujeitos usavam observação excêntrica devido a escotomas artificiais ou de ocorrência natural.

Os sacádicos exploratórios envolvem uma mudança na posição ocular após um deslocamento precedente da atenção espacial pela coordenação oculomotora, para o reconhecimento de objetos no campo visual, mesmo sob condições de aglomeração ou deslocamento desse alvo (74).

As alterações no comportamento de busca têm sido descritas em pacientes com dificuldades funcionais associadas a doenças como glaucoma (65,75-77), degeneração macular relacionada à idade (DMRI) (em que a dificuldade de leitura é observada) $(63,78)$, retinite pigmentosa (79) e acidente vascular cerebral (8083). As alterações perimétricas decorrentes de lesões retinianas podem, não só prejudicar a visão, restringindo o que o indivíduo vê no ambiente, mas também limitar a capacidade do sistema visual de estimular movimentos oculares eficientes (84). Uma busca visual eficiente proporciona agilidade e melhor desempenho em várias atividades visuais diárias (85). A melhor compreensão dos mecanismos envolvidos no processo de busca visual forneceu explicações para os distúrbios observados em certas condições neurológicas (86). No entanto, não há uma compilação abrangente de informações disponíveis até o momento para esclarecer a influência da deficiência visual sobre o desempenho em tarefas de busca visual.

A busca visual se dá por meio do mapeamento do ambiente com o intuito de identificar um objeto particular (alvo) em meio a outros objetos ou dentre um complexo arranjo de estímulos, denominados dispersores ou distratores (78). A habilidade para localizar objetos vem sendo progressivamente estudada nos 
últimos 40 anos $(87,88)$. Exemplos práticos dessa intrigante habilidade ocorrem rotineiramente na vida diária, quando se escolhe um produto na prateleira de um supermercado, se procura a identificação de um endereço na rua, se reconhece um rosto amigo em meio a outros, etc.

$\mathrm{Na}$ tarefa de busca visual ocorre um processo de autocoordenação dos movimentos sacádicos que, por meio de informações advindas da visão periférica, se repete até que o alvo desejado seja centralizado pela fóvea, e assim, encontrado $(66,69,75,89-91)$. Portanto, a visão periférica teria importância na busca visual quanto ao fornecimento das informações do meio ambiente (91-96), apesar de sua baixa resolução (97). Uma avaliação da visão periférica poderia apontar predisposição para capacidades visuais funcionais, como a rapidez na leitura, quando considerado que a eficiente coordenação dos sacádicos $(71,93)$ resultaria na melhor condução dos movimentos oculares, proporcionando 0 alinhamento do alvo para com a fóvea, local de alta resolução, durante os períodos de fixação (71). A capacidade de direção veicular segura envolveria, tanto a capacidade da visão central quanto da visão periférica, pois o reconhecimento espacial seria necessário para se garantir, não somente a visão ambiental, mas também a visão central, o que leva a se questionar o real critério de amplitude visual perimétrica necessária nos condutores (91).

Vários instrumentos de avaliação da busca visual usaram a movimentação ocular como forma de medir o grau de atenção despendido a um estímulo $(75,78)$. Entretanto, outros autores sugerem que a movimentação ocular ocorre independentemente da atenção. Por conseguinte, consideram que usar somente a movimentação ocular não é suficiente nem confiável para a avaliação do conjunto da busca visual, que acontece com ou sem os movimentos oculares $(93,98)$. O tempo de reação, ou seja, o tempo que se leva entre iniciar o processo de busca e o encontro do alvo, reflete o trabalho realizado para essa busca. Maior habilidade de busca apresenta menor tempo de reação e maior dificuldade de busca mostra maior tempo de reação (61). Assim, sugere-se que o tempo gasto para se detectar o alvo em meio aos seus dispersores seja um método de maior precisão $(99,100)$. 


\subsection{Glaucoma e o desempenho na busca visual}

Ao se analisar o resultado de testes diagnósticos baseados na busca visual, realizada primordialmente pela visão central, questiona-se o quanto um eventual mau desempenho pode decorrer da baixa percepção visual periférica, observada em doenças com perda perimétrica, tais com o glaucoma $(59,101$ 103). Alguns investigadores consideram os longos períodos de busca visual em testes com cenários naturais ou arranjos de optotipos, como provável consequência de perdas periféricas $(59,101)$. Smith, Crabb e Garway-Health (2011) (60) não encontraram diferenças nas avaliações quando utilizaram tabelas de optotipos, contudo em testes realizados com e sem restrição da visão periférica, observaram mudanças apenas no aumento do número de sacádicos, sem outras alterações oculomotoras $(102,103)$.

Nos últimos 15 anos, tem sido mais frequente a realização de estudos que procuram novos métodos para avaliar mudanças nas habilidades individuais de pacientes glaucomatosos com relação às atividades da vida diária. O objetivo é determinar detalhes desconhecidos acerca da evolução clínica e subjetiva da visão nesta doença. Outros métodos voltados ao estudo da busca visual têm se baseado na observação de sinais, sintomas e respostas a testes propostos para avaliação da capacidade em executar atos cotidianos, tais como: leitura com iluminação reduzida, reconhecimento de expressão facial, detecção de movimento, reconhecimento de sinais de rua, localização de objetos, deambulação, encaixe de peças nos locais de diferentes tamanhos, usar o telefone ou combinar a vestimenta $(21,30,39,59,61,71,104,105)$.

Poucos estudos sobre busca visual têm correlacionado 0 dano glaucomatoso com a sua repercussão social, por meio da associação entre as perdas apresentadas nos resultados dos exames diagnósticos e às dificuldades na execução de atividades diárias $(39,106)$. Além da perda de campo visual, a acuidade visual binocular e a sensibilidade ao contraste são aspectos da função visual que também dimensionam a capacidade do paciente com glaucoma em desenvolver suas atividades habituais $(30,39,77,107,108)$. Buscando verificar se há associação entre as mudanças na qualidade de vida, do ponto de vista do 
paciente, e o diagnóstico do glaucoma, o The Los Angles Latino Eye Study mostra que a pior qualidade de vida em pacientes com maior alteração perimétrica é tendência geral na população latina de Los Angeles $(21,109,110)$.

Com o objetivo de compreender a repercussão do glaucoma em aspectos mais práticos da função visual, tanto quantitativa quanto qualitativamente, é interessante a avaliação da atividade de busca visual em pacientes glaucomatosos, levando em consideração as diversas alterações visuais apresentadas, além do impacto dessas alterações na qualidade de vida desses pacientes.

O estudo dos movimentos sacádicos em tarefas de busca visual também tem sido usado para compreender melhor as repercussões funcionais relacionadas ao glaucoma $(14,60,75,104,105,111)$, uma vez que pacientes com glaucoma têm apresentado diminuição do número de movimentos sacádicos $(60,76,77,105)$. Assim, acredita-se que diferentes avaliações dos movimentos oculares (como a quantidade de sacádicos, o tempo de fixação e reação) no glaucoma podem contribuir com informações indiretas, mas seguras, sobre o estado funcional imposto pelo dano glaucomatoso $(42,76,105)$.

Questiona-se até que ponto o melhor entendimento acerca da deficiência em testes de busca visual serviria para se diagnosticarem casos precoces dessa doença (78). Nesses pacientes, as respostas a um teste de percepção, movimentação e orientação do estímulo visual exibido em um monitor de computador poderiam ser capazes de diferenciar casos normais daqueles com glaucoma inicial (112,113). Estudos voltados à correlação entre perdas perimétricas periféricas (de acordo com sua localização e extensão) e alterações nos movimentos naturais de busca visual têm mostrado que esses movimentos não foram afetados significativamente $(78,98)$. Frente à hipótese de que pacientes glaucomatosos com perdas visuais bilaterais apresentariam diferenças na busca visual, um estudo prévio analisou o desempenho na busca visual usando fotografias de cenas do cotidiano, observando fraca associação entre gravidade da perda perimétrica e desempenho de busca em regiões tipicamente vistas por sujeitos controles com visão normal (105). 
A leitura é um hábito diário na atualidade e envolve destreza da função de buscar alvos visuais em sequência, com rapidez e coordenação. Para avaliar até que ponto as pessoas com glaucoma têm dificuldades com a leitura e se há mudança na velocidade dessa leitura frente à diminuição do contraste do texto lido, Burton, Smith e Crabb (2014) (75) analisaram a hipótese de que os pacientes com glaucoma seriam mais sensíveis ao contraste em comparação com pessoas visualmente saudáveis, de mesma faixa etária e similar capacidade cognitiva de leitura. Utilizando um dispositivo de rastreamento ocular para registro dos movimentos, concluíram que a redução média na velocidade de leitura provocada por uma diferença de contraste do texto (de 100\% para $20 \%$ ) foi significativa nos pacientes com glaucoma $(75,114)$.

Neste contexto, Smith et al. (2014) (77) compararam a velocidade de leitura entre os olhos do mesmo paciente e observaram que esta velocidade foi significativamente menor e que o número de movimentos sacádicos de regressão (sacádicos retrógrados, de retomada da pesquisa de leitura) foi maior no olho com pior visão e maior defeito perimétrico. As diferenças interpessoais observadas no desempenho de leitura desses pacientes com glaucoma foram proporcionais à sua acuidade visual, mas não ao desvio médio de sensibilidade (do inglês mean deviation - MD) da PV, fato que torna essa associação mais intrigante.

Ao estudarem se as perdas perimétricas periféricas em motoristas idosos aumentaria a probabilidade de sofrer acidentes de trânsito, apontaram que fatores como acuidade visual, sensibilidade ao contraste, melhor visão periférica, maior área útil de visão, melhor estado mental e melhor saúde ocular se mostraram como fatores inversamente proporcionais ao risco de acidente de trânsito em idosos. A redução no campo de visão útil e a idade foram fatores preditivos na ocorrência de acidentes, mas não significativos para discriminar motoristas envolvidos ou não em acidentes $(53,54,115)$. 


\subsection{Justificativa}

Considerando o pouco conhecimento acerca dos mecanismos envolvidos nas diversas formas de alterações visuais observadas no glaucoma, em especial aquelas indiretamente relacionadas aos danos perimétricos glaucomatosos, tornase interessante o aprofundamento em questões relacionadas, de forma mais direta, à vida diária dos pacientes acometidos por esta doença, tais como a busca visual.

Assim, propõe-se comparar o desempenho em tarefas de busca visual de pacientes com GPAA e sujeitos saudáveis, levando em conta a distribuição espacial das diversas alterações perimétricas observadas na doença, uma vez que tal correlação não foi diretamente estudada até o momento. 
2. Objetivos 


\subsection{Objetivo geral}

Estudar o desempenho de busca visual em tarefas padronizadas de pacientes com GPAA e perdas perimétricas variadas.

\subsection{Objetivos específicos}

- Comparar o tempo de busca visual em plataforma digital padronizada entre dois grupos, sendo um composto por sujeitos saudáveis e outro por pacientes com GPAA, ambos com acuidade visual normal.

- Correlacionar espacialmente os defeitos perimétricos e as diferenças no tempo de busca visual dos estímulos localizados nas áreas desses defeitos, em pacientes com GPAA e acuidade visual normal. 
3. Casuistica e Métodos 


\subsection{Aspectos Éticos}

O presente estudo foi aprovado pelo Comitê de Ética em Pesquisa do Hospital das Clínicas da Faculdade de Medicina de Ribeirão Preto da USP (HCFMRP-USP), Processo no 660.663 (Anexo A).

Todos os participantes submetidos aos procedimentos da pesquisa assinaram o Termo de Consentimento Livre e Esclarecido (TCLE) (Anexo B), após receberem detalhadas explanações sobre todos os procedimentos relacionados, seus potenciais efeitos benéficos e complicações, além de seu caráter voluntário. Este estudo não incorreu em qualquer prejuízo, lesões ou desconforto aos seus participantes.

\subsection{Amostra}

Para cálculo do tamanho da amostra, foram considerados os resultados obtidos por Smith, Crabb e Garway-Health (2011) (60). Para se detectar uma diferença no tempo de busca visual de 5,2 s, aceitando um desvio padrão (DP) de $5,4 \mathrm{~s}$, para um alpha de 0,05 e poder do teste de $90 \%$, 24 participantes seriam necessários em cada grupo. Assim, a proposta inicial foi de recrutar 29 sujeitos em cada grupo, a fim de se considerarem $20 \%$ de perdas.

Sessenta e seis voluntários foram recrutados do Setor de Oftalmologia Geral e do Ambulatório de Glaucoma do HCFMRP-USP, no período de junho de 2014 a maio de 2016, e os participantes foram divididos em dois grupos:

1. Grupo GPAA, composto por trinta e três pacientes com GPAA;

2. Grupo CONTROLE, formado por 33 indivíduos normais, sem alterações na PV.

Neste estudo, optou-se pelo exame de um olho de cada paciente (olho esquerdo), na tarefa de busca visual, considerando as limitações técnicas relacionadas à aquisição dos dados. 


\subsection{Critérios de inclusão}

\subsubsection{Gerais}

Foram incluídos sujeitos de ambos os sexos; com idade entre 40 e 80 anos; com ausência de incapacidade cognitiva, possibilidade de comparecer a todas as visitas para avaliações, capacidade de realizar todos os exames necessários e ausência de comorbidades sistêmicas em estado grave ou controle inadequado, como por exemplo: Diabetes Mellitus, Hipertensão Arterial Sistêmica, dislipidemias, alterações hormonais, cardiopatias, vasculopatias, doenças neurodegenerativas e tumores sistêmicos, dentre outras.

\subsubsection{Oftalmológicos}

\section{Para ambos os grupos:}

- Eixo visual livre, sem opacidades que impedissem os exames oftalmológicos;

- Ausência de qualquer comorbidade ocular que potencialmente interferisse nas avaliações ou na função visual, como por exemplo, retinopatias, catarata, opacidades de córnea, alterações de anexos oculares, afecções neuro-oftalmológicas, complicações de cirurgia de catarata, tumores e inflamações intraoculares, dentre outros.

- Pacientes com refração esférica igual ou inferior a $\pm 6 \mathrm{D}$ e cilíndrica igual ou inferior a 3D;

- Ausência de outras cirurgias oftalmológicas prévias, à exceção de trabeculectomia e facectomia, se realizadas há mais de doze meses;

- Pacientes com a acuidade visual corrigida (AVCC) em olho esquerdo $\geq 0,2 \log M A R$;

- Ângulo categorizado como aberto, sem alterações patológicas visíveis à gonioscopia. 


\section{Para o grupo GPAA:}

- Diagnóstico em prontuário médico de GPAA, segundo os critérios de Hodapp-Parrish-Anderson $(29,107,116)$ e Schimiti et al. (116), e com exame oftalmológico demonstrando:

$\checkmark \mathrm{PIO}>21 \mathrm{mmHg}$ em pelo menos três tonometrias realizadas em dias diferentes com tonômetro de Goldmann, com ou sem medicação antiglaucomatosa;

$\checkmark$ Relação E/D $\geq 0,6$, avaliada pela biomicroscopia de fundo em lâmpada de fenda, com a presença de pelo menos um dos sinais localizatórios relacionados ao glaucoma (Hoyt, Notch, assimetria da relação $E / D>0.2$, hemorragia de disco, alteração da sequência ISNT, atrofia peripapilar, fosseta adquirida de nervo óptico, vasos em passarela, baioneta, anasalados ou colaterais, aumento das estrias da lâmina crivosa e escavação nasal);

$\checkmark$ PV computadorizada realizada nos últimos seis meses, dita baseline, com a estratégia 24-2 Swedish Interactive Threshold Algorithm (SITA - STANDARD; Humphrey Visual Field Analyzer 750, Carl Zeiss, Dublin, California), com a adequada correção óptica, apresentando ao menos uma entre as três condições: três ou mais pontos adjacentes com $p<5 \%$ (no gráfico pattern deviation [PD]), sendo pelo menos um ponto com $p<1 \%$; GHT com descrição outside normal limits ou borderline; índice do desvio padrão (PSD) com nível $<5 \%(29,52,111)$. Apenas os exames com dados apresentando confiabilidade permaneceram no estudo, sendo considerado como exame não-confiável a presença de perdas de fixação superiores a $20 \%$, respostas falsopositivas superiores a $30 \%$ e respostas falso-negativas superiores a $30 \%(117,118)$. 


\subsection{Critérios de exclusão}

- Pacientes que não preencheram os critérios de inclusão acima descritos;

- Pacientes com incapacidade cognitiva ou de participação;

- Pacientes, cujo um ou mais exames não apresentaram resultados confiáveis;

- Pacientes que, por algum motivo não realizaram todos os exames do protocolo de estudo;

- Comorbidades oculares e/ou sistêmicas em estado grave.

\subsection{Protocolo de exames}

Todos os participantes foram submetidos à sequência de exames: oftalmológico clínico, PV computadorizada (Humphrey Visual Field Analyzer 750, Carl Zeiss, Dublin, California), tomografia de coerência óptica (OCT) de domínio espectral SD-OCT (Spectralis OCT, Heidelberg Engeneering, Heidelberg, Alemanha) e busca visual. Todos os exames foram aplicados pelo mesmo examinador, no mesmo equipamento e local. $O$ exame oftalmológico clínico incluiu avaliações de AVCC, motilidade, refração, biomicroscopia, tonometria e gonioscopia.

\subsubsection{Perimetria visual computadorizada}

Todos os pacientes foram submetidos ao exame de PV computadorizada, 24-2 Swedish Interactive Threshold Algorithm (estratégia SITA-STANDARD), com a adequada correção óptica para perto, pelo mesmo profissional técnico. Para fins de avaliação, foram consideradas quaisquer alterações dos índices globais e do gráfico PD, sendo o presente exame tomado como padrão para o indivíduo. 


\subsubsection{Busca visual (Teste de estímulos visuais em plataforma computacional)}

Para realizar a tarefa de busca de dígitos, utilizou-se um software personalizado (Borland Delphi 7.0 - FOUR®) (90), cuja função é produzir um arranjo aleatório de dígitos (0-9, em fonte Arial preta, tamanho 14) apresentados em um monitor com $70 \mathrm{~cm}$ de largura e $40 \mathrm{~cm}$ de altura e fundo branco, com igual probabilidade de distribuição em todas as localizações. Nesse monitor, o tamanho dos dígitos foi de $5 \mathrm{~mm}$, equivalente a $6 \mathrm{M}$ (Figura 4). De modo sequencial, nove telas diferentes e aleatórias foram exibidas para cada participante. Completavam o equipamento um mouse, uma mesa de apoio, uma queixeira e um oclusor oftálmico para o olho direito do examinado.

Figura 4 - Fotografia da tela com o programa Four em execução, com os dígitos aleatoriamente apresentados.

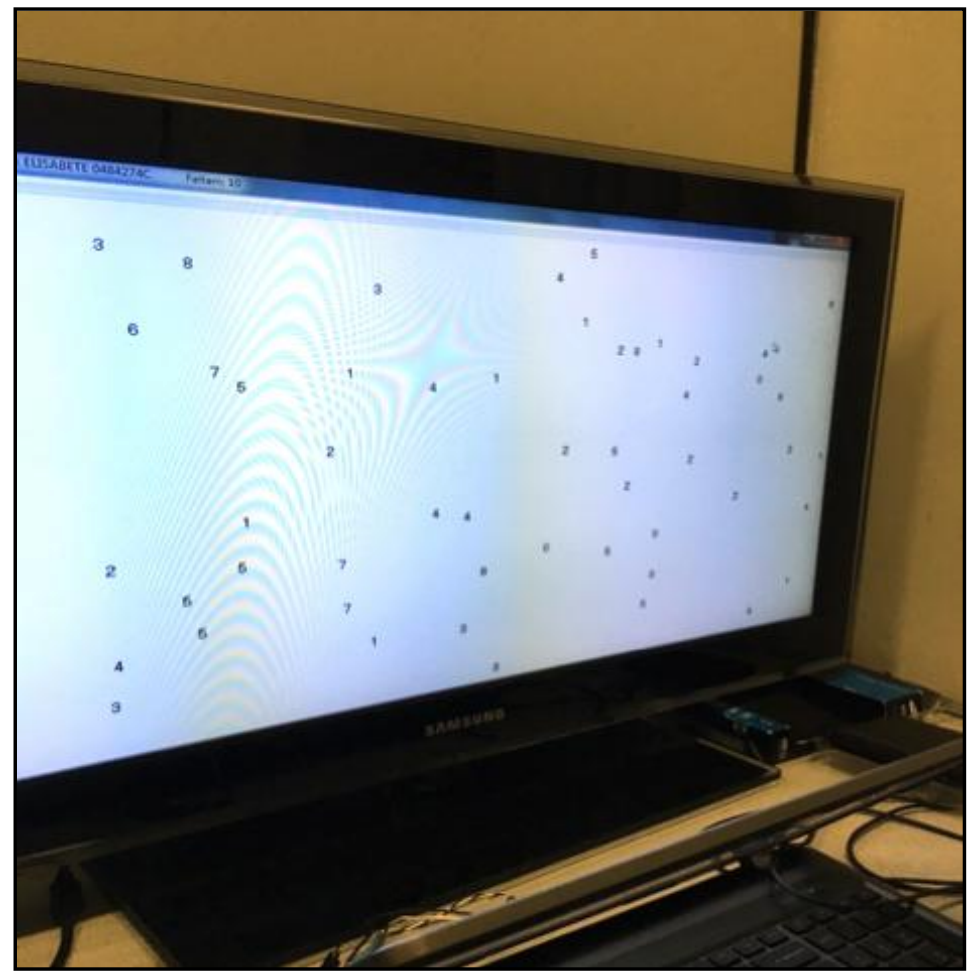


Os exames se iniciavam com o correto posicionamento do examinado, sentado confortavelmente em frente à tela, com o olho direito ocluído e o esquerdo com a visão corrigida para perto, a face posicionada na queixeira, de modo que o olho esquerdo ficasse centralizado em relação a um estímulo central, previamente apresentado na tela inicial, mantendo a distância fixa de $62 \mathrm{~cm}$ entre a tela e o olho esquerdo (Figura 5).

Figura 5 - Esquema demostrando as dimensões entre o olho examinado e a tela usada para o teste de busca visual. À esquerda, a tela com dimensões de $70 \times 40 \mathrm{~cm}$. À direita, o indivíduo com correção para perto, olho direito ocluído, olho esquerdo centralizado na tela, a $62 \mathrm{~cm}$ de distância.

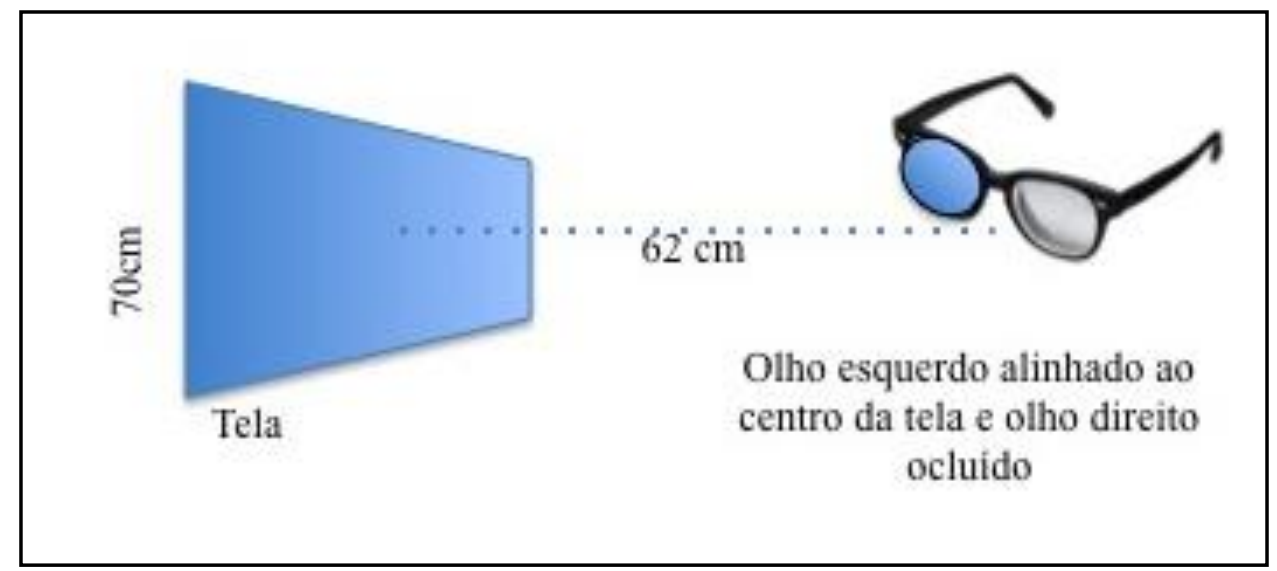

Após explicação detalhada sobre o andamento do exame e treinamento em uma tela não utilizada na análise dos dados, o exame era iniciado. O examinado, então, dava início ao exame de busca visual ao clicar com o mouse na posição do botão virtual central da tela e o programa realizava automaticamente o preenchimento aleatório da tela com os dígitos. Nesse programa, os participantes procuravam os dígitos alvo (sendo o dígito "4" considerado como alvo) e por meio da movimentação do mouse com a mão dominante, marcavam esse alvo ao passar o cursor sobre ele. Nesse momento, o programa alterava a cor da fonte do dígito alvo para vermelha e impedia a duplicidade de procura para o mesmo elemento (Figuras 6 e 7 ). 
Figura 6 - Fotografia de uma tela em execução do programa Four, com sujeito em exame.

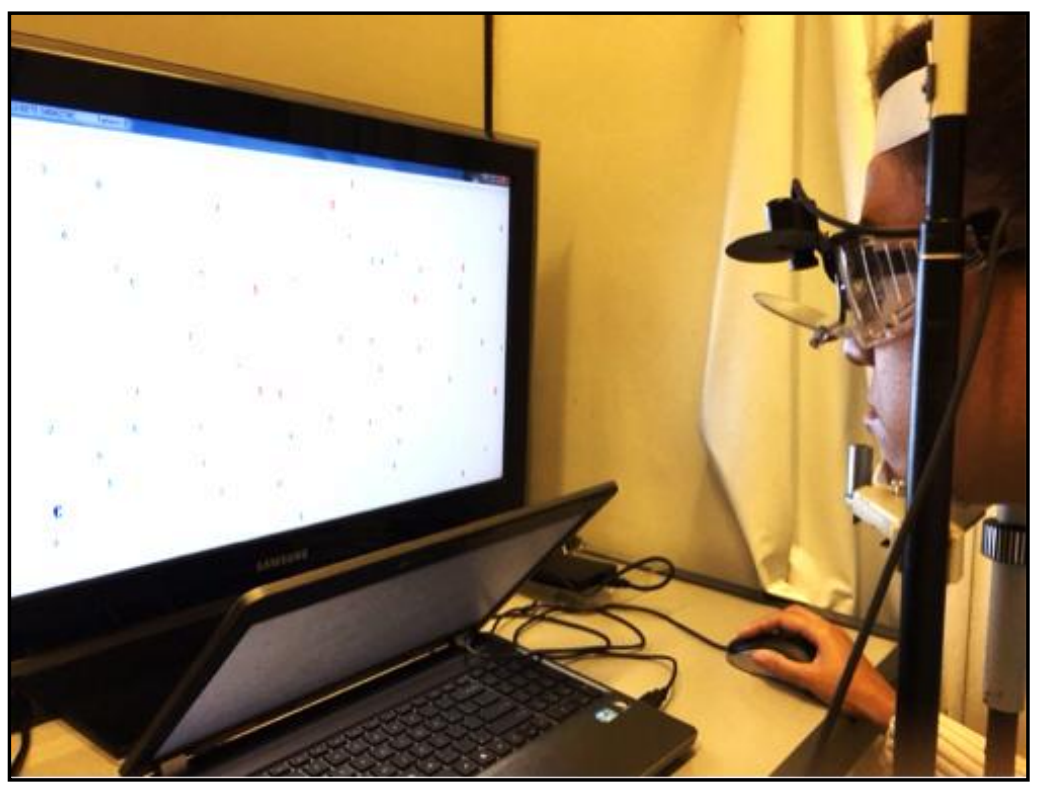

Figura 7 - Foto de um paciente do grupo GPAA em exame, sentado, com a face posicionada na queixeira, olho direito ocluído e olho esquerdo centralizado na tela.

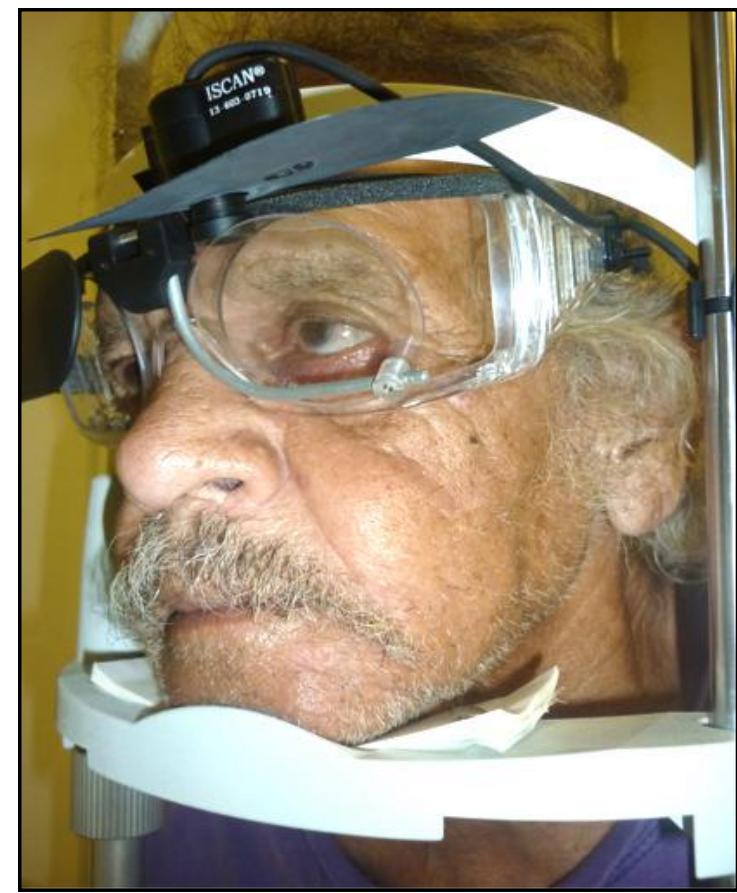


Após encontrar todos os alvos de determinada tela, uma nova tela foi reiniciada automaticamente e o indivíduo seguiu para as próximas fases do teste, mirando e clicando no botão central, sucessivamente, até completar 10 telas. Variáveis como a localização na tela (coordenadas do dígito alvo - dadas em padrão x, y e apresentadas em pixels); o tempo total (tempo de resposta de busca ou tempo gasto para o encontro de todos os alvos) e o tempo individual (tempo de resposta de busca ou tempo gasto para o encontro de cada alvo individualmente) foram coletadas de todas as telas e armazenadas em uma base de dados para análise. Apenas participantes com exames com dados apresentando mínima confiabilidade permaneceram no estudo. Os critérios de mínima confiabilidade ram 1) perda da posição inicial da cabeça na queixeira; 2) tempo de exame maior que 15 minutos; 3) abandono do exame antes de sua conclusão.

\subsection{Análise dos resultados}

Além de descrições dos achados do campo visual e busca visual em cada grupo, realizou-se a análise de correlação direta entre parâmetros globais (idade, AVCC, MD, PSD e tempos de busca total e individual). Adicionalmente, estabeleceu-se correspondência espacial entre o desempenho no exame de busca visual e o exame perimétrico, com base em relações trigonométricas simples, visando a padronização da localização espacial dos achados. Dessa forma, a tela do exame de busca visual, bem como o gráfico total deviation (TD) da PV foram setorizados de modo correspondente. Para tanto, determinou-se a abertura do ângulo visual nos extremos da tela usada para o exame de busca visual. Considerando a centralização da pupila do olho examinado em relação ao alvo central, a distância fixa de $62 \mathrm{~cm}$ e as dimensões da tela $(40 \times 70 \mathrm{~cm})$, foram obtidos ângulos de abertura vertical de $18^{\circ}$ (tg $\partial$ (vertical $)=20 / 62=0.32$, correspondente a $18^{\circ}$ ) e horizontal de $30^{\circ}$ (tg $B$ (horizontal) $=35 / 62=0.54$, correspondente a $\left.30^{\circ}\right)$ (Figura 8 ). 
Figura 8 - Desenho esquemático demonstrando as relações utilizadas para cálculos de correspondência em termos de amplitude de campo de visão vertical e horizontal na tela usada para busca visual, considerando a distância fixa entre o olho examinado e o centro da tela.

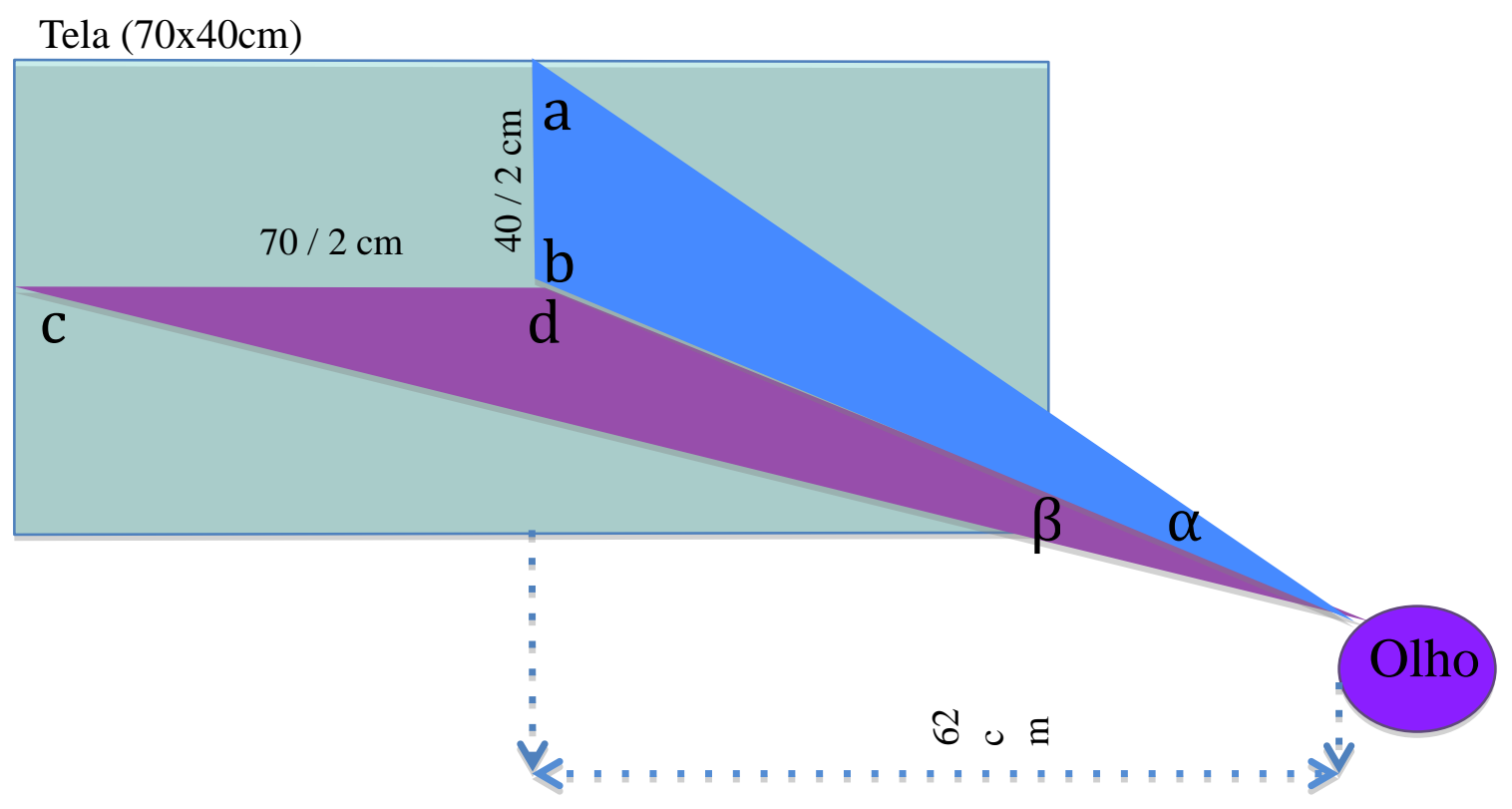

Tem-se, então, que a tela do exame de busca visual abrange uma área de amplitude vertical de $36^{\circ}$, sendo $18^{\circ}$ para cima e $18^{\circ}$ para baixo do centro, e $60^{\circ}$ horizontais, sendo $30^{\circ}$ para a esquerda e $30^{\circ}$ para a direita do centro. Dessa forma, dividiu-se a tela em quatro áreas, traçando-se linhas perpendiculares através do ponto central. A região central da tela contém um ponto central desta e está limitada por um traçado compreendendo os 10 graus centrais do gráfico TD da PV e foi nomeada de área central (CEN). Com tal subdivisão, quatro áreas ditas periféricas foram propostas: periférica supero-nasal (PSN); periférica superotemporal (PST); periférica ínfero-temporal (PIT) e periférica ínfero-nasal (PIN) (Figura 9). 
Figura 9 - Divisão da tela do exame de busca visual, que abrange 36 graus verticalmente e $60^{\circ}$ horizontalmente, do campo visual central. As cinco áreas são correspondentes com as áreas perimétricas.

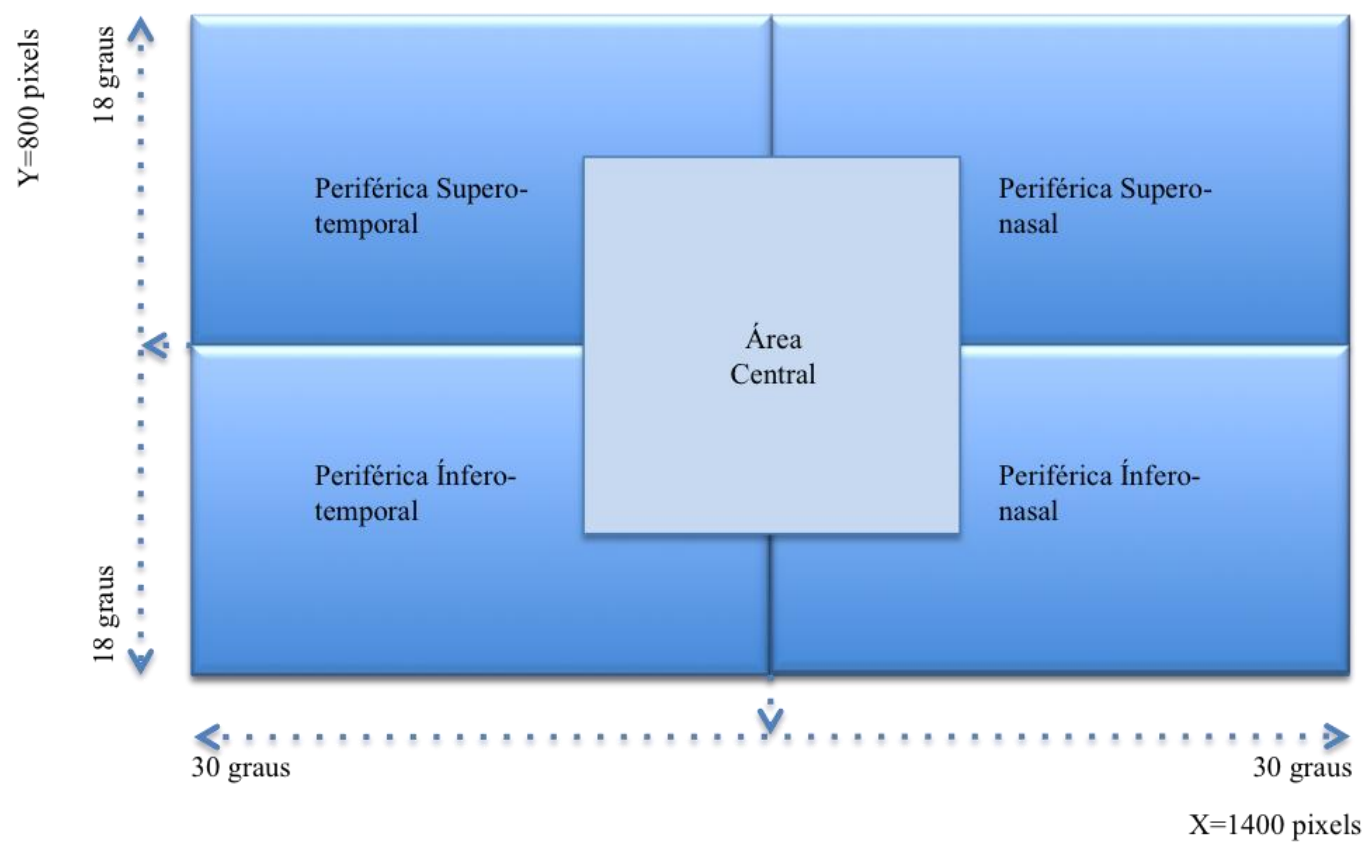

De modo a facilitar a análise comparativa espacial e considerando que apenas olhos esquerdos foram usados, todos os pontos da PV receberam arbitrariamente numeração ordenada de identificação, com início a partir do primeiro ponto superior esquerdo do lado nasal, seguindo-se da esquerda para a direita, de cima para baixo, até o último ponto inferior à direita do lado nasal. Então, do mesmo modo, numerou-se sequencialmente o lado temporal, totalizando 52 pontos, conforme demonstrado na Figura 10. Assim, considerando os limites angulares da tela de busca visual $\left(60^{\circ} \times 36^{\circ}\right)$, aplicados no gráfico TD, e a sequência construída, foi possível conhecer os pontos pertencentes a cada área de interesse (CEN, PSN, PIN, PST, PIT) e correlaciona-los à tela do exame de busca visual. Apenas quatro pontos de estímulos da PV no hemicampo superior (números 29, 30, 1 e 2) e quatro no inferior (números 51, 52, 27 e 28) não apresentaram correspondência, quando correlacionados espacialmente (Figura 10).

Os 44 pontos que se encontravam dentro da área de interesse (pertencentes ao retângulo da Figura 1, foram divididos nos cinco setores, do 
mesmo modo que a tela do exame de busca visual. A média dos valores observados nos 16 pontos centrais do TD (36, 37, 6, 7, 39, 40, 10, 11, 42, 43, 15, 16, 46, 47, 20 e 21) compôs a variável TD CEN; nos oito pontos nasais superiores (3 a 5, 8, 9, 12 a 14), a TD PSN; nos oito pontos nasais inferiores periféricos (17 a 19, 22, 23, 24 a 26), a TD PIN; nos seis pontos temporais superiores periféricos (31 a 35, 38), a TD PST; e nos seis pontos temporais inferiores periféricos (pontos 41, 44, 45, 48 a 50), a TD PIT, respectivamente. Também foram utilizados os valores MD e PSD, em decibéis ( $d B)$.

Figura 10 - Gabarito para análise de confrontação entre a sensibilidade perimétrica $\mathrm{x}$ desempenho de busca na tela do exame de busca visual padronizada.

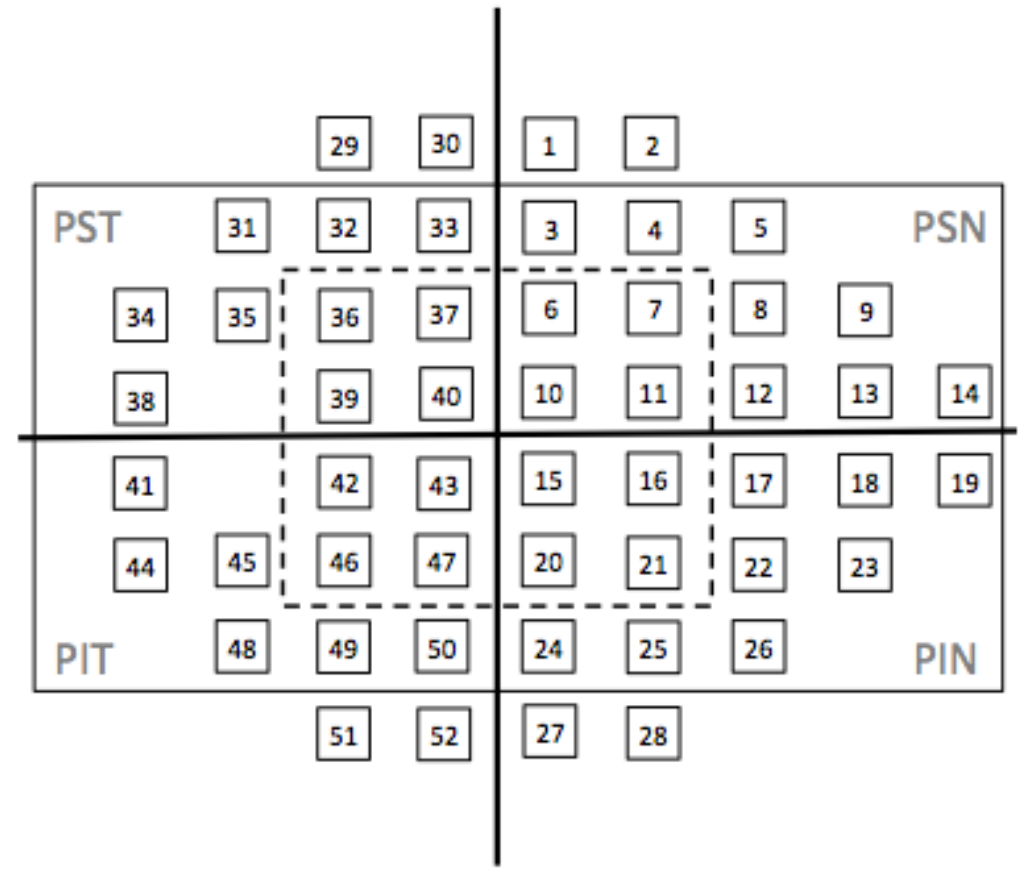

O software SAS ${ }^{\circledR}$ JMP $10.0^{\circledR}$ (SAS Institute Inc., NC, USA) foi utilizado para análise estatística complementar das telas do teste de busca visual. Por meio do reconhecimento da localização geográfica e da ordenação dos pontos da PV, o conjunto de dados de ambos os testes puderam ser correlacionados em cada participante. Tal análise permitiu o entendimento dos dados como o tempo gasto para o encontro de cada alvo e a sua localização na tela, ou seja, saber a ordem, 
o tempo, o local do estímulo e sua futura correlação com os achados correspondentes da PV (Figura 11).

Figura 11 - Representação esquemática do exame de busca visual, com a localização de cada alvo apresentado e sua ordenação temporal quanto à sua identificação pelo participante, ao longo do exame (por meio das cores e tamanhos das esferas).

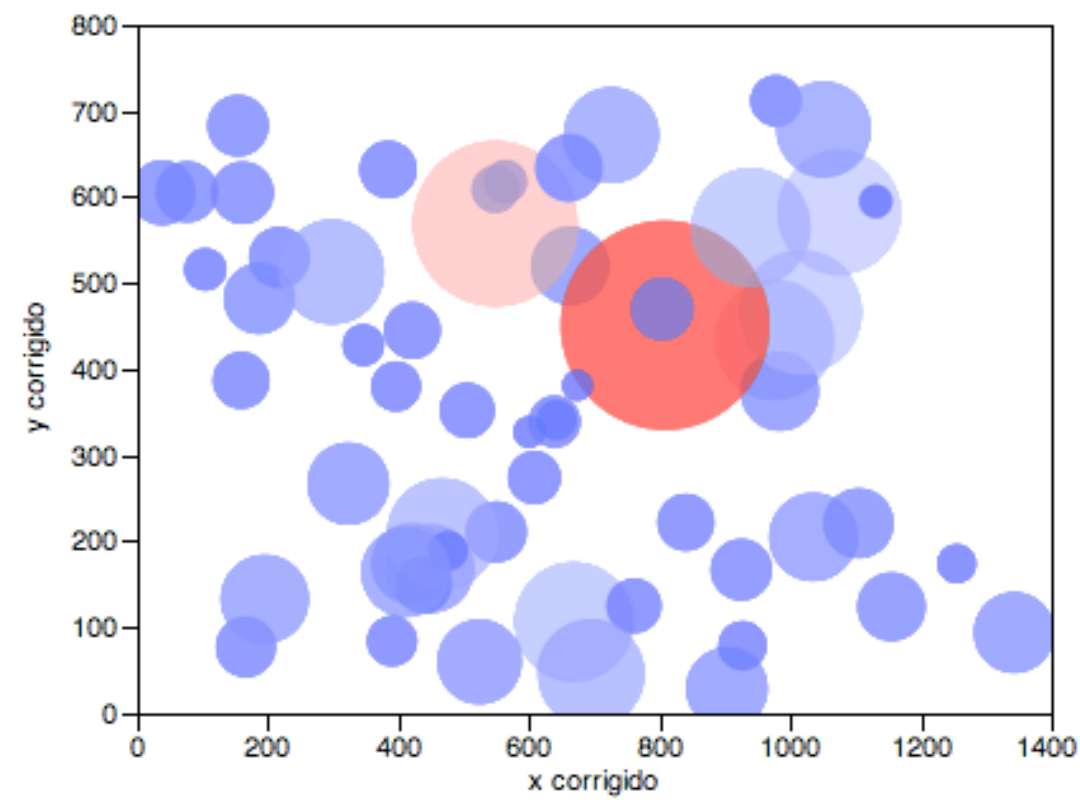

\subsection{Variáveis do Estudo}

Dados de todos os participantes de ambos os grupos foram analisados e confrontados por meio do estudo das seguintes variáveis:

- Gênero (Masculino, Feminino), idade (anos), AVCC (logMAR), PIO $(m m H g)$, relação $E / D$, espessura da RNFL $(\mu m)$;

- Variáveis do exame de PV, em dB: média do MD e PSD, sensibilidade média por área: área central (TD CEN), periférica ínfero-nasal (TD PIN), periférica supero-nasal (TD PSN), periférica ínfero-temporal (TD PIT) e periférica supero-temporal (TD PST);

- Variáveis do teste de busca visual, em segundos: média do tempo total do exame (média do Tempo Total); média do tempo gasto para 
identificar cada alvo no conjunto das cinco áreas (média do Tempo individual Global - TIG); tempo gasto para identificar cada alvo por área da tela: central (média do Tempo individual CEN); periférica ínfero-nasal (Tempo individual PIN); periférica supero-nasal (Tempo individual PSN); periférica ínfero-temporal (Tempo individual PIT) e periférica supero-temporal (Tempo individual PST).

\subsection{Análise estatística}

Os dados coletados foram descritos por meio de parâmetros usuais de estatística descritiva, frequências, médias e DP. Devido à natureza dos dados, os grupos foram comparados utilizando testes não-paramétricos para dados sem distribuição normal, ou paramétricos para dados com distribuição normal. Ainda, tabelas de contingência para dados categóricos e testes de correlação foram aplicados quando apropriados. As variáveis de interesse apresentando correlação estatística na análise univariada foram avaliadas por testes multivariados de covariância (ANCOVA). Os softwares Prism 5.0 (Software Inc., CA, EUA) e SAS ${ }^{\circledR}$ JMP $10.0^{\circledR}$ (SAS Institute Inc., NC, USA) foram utilizados para toda análise estatística. Os resultados foram considerados estatisticamente significativos quando $\mathrm{p}<0.05$. 
4. Resultados 


\subsection{Dados demográficos e clínicos}

Sessenta e cinco sujeitos foram avaliados, sendo excluídos oito por não conseguirem realizar os exames com a confiabilidade exigida neste estudo (em parâmetros da perimetria visual, $n=4$; e nos de busca visual, $n=4$ ). Cinquenta e sete $(86,4 \%)$ participantes concluíram o estudo, compondo o grupo GPAA $(n=29)$ e o grupo CONTROLE $(n=28)$. O grupo GPAA não diferiu do grupo CONTROLE quanto ao sexo, à idade, AVCC e PIO. O grupo GPAA apresentou relação E/D maior que o grupo CONTROLE (média \pm desvio padrão: 0,75 \pm 0,142 vs 0,32 \pm 0,053, respectivamente; $p<0,0001)$, bem como menor espessura da RNFL $(73,0 \pm$ $15,48 \mu \mathrm{m}$ vs 102,5 \pm 9,03 $\mu \mathrm{m} ; \mathrm{p}<0,0001$ ) (Tabela 2).

Tabela 2 - Dados demográficos, condições gerais e características clínicas dos sujeitos estudados

\begin{tabular}{llll}
\hline \multicolumn{1}{c}{ Dados } & \multicolumn{1}{c}{$\begin{array}{c}\text { GPAA } \\
(\mathbf{n = 2 9 )}\end{array}$} & $\begin{array}{c}\text { CONTROLE } \\
(\mathbf{n = 2 8})\end{array}$ & P \\
\hline Gênero (masculino: feminino) & $13: 16$ & $9: 19$ & 0,4173 \\
Idade (anos) & $61,72 \pm 11,39$ & $56,36 \pm 10,63$ & 0,0715 \\
AVCC (logMAR) & $0,082 \pm 0,088$ & $0,053 \pm 0,069$ & 0,2276 \\
PIO (mmHg) & $14,90 \pm 3,37$ & $13,68 \pm 1,65$ & 0,0910 \\
Relação E/D & $0,758 \pm 0,142$ & $0,328 \pm 0,053$ & $<0,0001$ \\
Espessura da RNFL $(\mu \mathrm{m})$ & $73,07 \pm 15,48$ & $102,50 \pm 9,03$ & $<0,0001$
\end{tabular}

Gênero: descrito em proporção masculino: feminino; Os demais resultados são descritos em valores de media \pm desvio-padrão; $A V C C=$ melhor acuidade visual corrigida; $\mathrm{PIO}=$ pressão intraocular; relação $\mathrm{E} / \mathrm{D}=$ relação escavação vertical/diâmetro disco óptico; RNFL= camada de fibras nervosas da retina.

\subsection{Perimetria Visual}

O grupo GPAA apresentou MD significativamente maior $(-8,02 \pm 7,88 \mathrm{~dB}$ vs $-1,43 \pm 1.50 \mathrm{~dB} ; \mathrm{p}<0,0001)$, maior média do PSD $(+4,74 \pm 3,47 \mathrm{~dB}$ vs $+1,81 \pm 0,51$ $d B ; p<0,0001)$ que o grupo CONTROLE. O grupo GPAA demonstrou ainda piores médias de sensibilidade nas cinco áreas estudadas da PV: área central (média de 
TD CEN $=-7,52 \pm 7,28 \mathrm{~dB}$ vs -0,45 $\pm 1,11 \mathrm{~dB} ; \mathrm{p}<0,0001)$, periférica ínfero-nasal (média de TD PIN = -4,97 $\pm 4,78 \mathrm{~dB}$ vs $-1,11 \pm 1,53 \mathrm{~dB} ; \mathrm{p}=0,0007$ ), periférica ínferotemporal (média de TD PIT $=-2,86 \pm 2,98 \mathrm{~dB}$ vs $-0,33 \pm 1,03 \mathrm{~dB} ; \mathrm{p}<0,0001$ ), periférica ínfero-nasal (média de TD PIN = -4,97 $\pm 4,78 \mathrm{~dB} v s-1,11 \pm 1,53 \mathrm{~dB}$; $\mathrm{p}=0,0007$ ) e periférica supero-temporal (média deTD PST $=-2,67 \pm 2,71 \mathrm{~dB}$ vs $-0,71 \pm 1,23 \mathrm{~dB} ; \mathrm{p}=0,0002)$ (Tabela 3).

Tabela 3 - Valores médios de sensibilidade globais e nas áreas estudadas da perimetria visual, por grupo

\begin{tabular}{lccc}
\hline \multicolumn{1}{c}{ Data } & GPAA & CONTROLE & P \\
\hline MD(dB) & $-8,02 \pm 7,88$ & $-1,43 \pm 1,50$ & $<0,0001$ \\
PSD $(\mathrm{dB})$ & $+4,74 \pm 3,47$ & $+1,81 \pm 0,51$ & $<0,0001$ \\
Média de TD CEN(dB) & $-7,52 \pm 7,28$ & $-0,45 \pm 1,11$ & $<0,0001$ \\
Média de TD PIN(dB) & $-4,97 \pm 4,78$ & $-1,11 \pm 1,53$ & 0,0007 \\
Média de TD PSN(dB) & $-4,25 \pm 4,57$ & $-1,16 \pm 1,58$ & 0,0173 \\
Média de TD PIT(dB) & $-2,86 \pm 2,98$ & $-0,33 \pm 1,03$ & $<0,0001$ \\
Média de TD PST(dB) & $-2,67 \pm 2,71$ & $-0,71 \pm 1,23$ & 0,0002
\end{tabular}

$\mathrm{MD}=$ desvio médio em $\mathrm{dB} ; \mathrm{PSD}=$ desvio-padrão da sensibilidade média em $\mathrm{dB}$; $\mathrm{TD}=$ total deviation; $\mathrm{CEN}=$ área central; $\mathrm{PIN}=$ área periférica ínfero-nasal; $\mathrm{PSN}=$ área periférica supero-nasal; $\mathrm{PIT}=$ área periférica ínfero-temporal; PST = área periférica supero-temporal.

\subsection{Busca Visual}

O Tempo Total médio do grupo GPAA foi aproximadamente o dobro do observado no grupo CONTROLE $(106,4 \pm 59,64 \mathrm{~s}$ vs 52,75 $\pm 19,07 \mathrm{~s}$, respectivamente, $p<0,0001)$. A média dos tempos para a identificação de cada alvo também foi maior no grupo GPAA (Média do TIG $=6,525 \pm 3,790$ s vs $3,061 \pm 1,341 \mathrm{~s} ; \mathrm{p}<0,0001)$, bem como dos tempos gastos para a identificação de cada alvo em todas as cinco áreas da tela (área CEN 5,298 $\pm 3,335$ s vs 2,690 $\pm 1,063 \mathrm{~s}, \mathrm{p}=0,0015$; área PIN 6,516 $\pm 4,054$ s vs 3,298 $\pm 1,403 \mathrm{~s}, \mathrm{p}=0,0007$; área PSN 7,332 $\pm 5,796 s$ vs 2,670 $\pm 1,017 s, \quad \mathrm{p}<0,0001$; área PIT $6,331 \pm 3,540 s$ vs $3,166 \pm 1,544 \mathrm{~s}, \mathrm{p}<0,0001$; área PST $7,151 \pm 4,381$ s vs $3,479 \pm 3,313 \mathrm{~s}, \mathrm{p}<0,0001$ ). 
Analisando por área, o tempo individual entre os grupos apresentou maior diferença entre as áreas PSN e menor diferença entre as áreas CEN (Tabela 4).

Tabela 4 - Distribuição dos valores médios de tempo total e individual global e nas áreas estudadas para busca visual, por grupo

\begin{tabular}{lccc}
\hline \multicolumn{1}{c}{ Data } & GPAA & CONTROLE & p \\
\hline Média do tempo Total(s) & $106,4 \pm 59,64$ & $52,75 \pm 19,07$ & $<0,0001$ \\
Média do tempo Individual Global(s) & $6,525 \pm 3,790$ & $3,061 \pm 1,341$ & $<0,0001$ \\
Média do tempo Individual CEN(s) & $5,298 \pm 3,335$ & $2,690 \pm 1,063$ & 0,0015 \\
Média do tempo Individual PIN(s) & $6,516 \pm 4,054$ & $3,298 \pm 1,403$ & 0,0007 \\
Média do tempo Individual PSN(s) & $7,332 \pm 5,796$ & $2,670 \pm 1,017$ & $<0,0001$ \\
Média do tempo Individual PIT(s) & $6,331 \pm 3.540$ & $3,166 \pm 1,544$ & $<0,0001$ \\
Média do tempo Individual PST(s) & $7,151 \pm 4,381$ & $3,479 \pm 3,313$ & $<0,0001$ \\
\hline
\end{tabular}

GPAA= Grupo de pacientes; CONTROLE= Grupo controle; tempo Total= tempo total das nove telas do exame, em segundos; Individual Global= tempo gasto para identificar cada alvo apresentado no exame, abrangendo as cinco áreas da tela; $\mathrm{CEN}=$ área central; $\mathrm{PIN}=$ área periférica ínfero-nasal; $\mathrm{PSN}=$ área periférica supero-nasal; $\mathrm{PIT}=$ área periférica ínfero-temporal; $\mathrm{PST}=$ área periférica superotemporal.

\subsection{Correlações entre busca visual, idade, sexo, acuidade visual e perimetria visual}

Sendo o tempo gasto para identificar cada alvo na tela considerado o parâmetro de busca visual mais refinado na interpretação desse fenômeno por meio da plataforma utilizada, os resultados do TIG foram relacionados a fatores potencialmente associados a esse fenômeno. Os testes de Spearman mostraram correlação significativa com o MD, a Idade e a AVCC (Tabela 5). Não houve diferença na comparação do TIG de busca visual e gênero (Grupo GPAA, $\mathrm{p}=0,218$; Grupo CONTROLE, $\mathrm{p}=0,266)$. 
Tabela 5 - Correlações entre os resultados dos tempos individual global de busca visual, MD, AVCC e idade

\begin{tabular}{lcccc}
\hline \multicolumn{1}{c}{ Variáveis } & TIG $\mathbf{r}(\mathbf{p})$ & MD $\mathbf{r}(\mathbf{p})$ & Idade $\mathbf{r}(\mathbf{p})$ & AVCC $\mathbf{r}(\mathbf{p})$ \\
\hline TIG & 1,00 & -- & -- & -- \\
MD & $-0,47(<0,01)$ & 1,00 & -- & -- \\
Idade & $0,59(<0,01)$ & $-0,38(<0,01)$ & 1,00 & \\
AVCC & $0,53(<0,01)$ & $-0,27(0,04)$ & $0,58(<0,01)$ & 1,00
\end{tabular}

Utilizado o Teste de correlações de Spearman r.; TIG= Tempo Individual Global, média de tempo gasto para identificação de cada alvo entre as nove telas do exame, em segundos; $M D=$ desvio médio em dB; $A V C C=$ melhor acuidade visual corrigida.

Considerando os resultados observados, procedeu-se a análise de covariância (ANCOVA) para o TIG, tendo como fatores: MD, AVCC, idade e grupo. Observou-se correlação significativa entre este tempo de busca e pior AVCC e à condição de não pertencer ao grupo CONTROLE (Tabela 6).

Tabela 6 - Análise de covariância para correlação do tempo individual global de busca visual com MD, AVCC, idade e grupo de estudo

\begin{tabular}{lcccc}
\hline \multicolumn{1}{c}{ Fator } & Estimativa & DP & t & Prob $>|\mathbf{t}|$ \\
\hline Intercepto & 53,317 & 2008,972 & 0,03 & $0,9789^{*}$ \\
MD & $-83,667$ & 61,333 & $-1,36$ & 0,1784 \\
AVCC & 14618,754 & 5135,617 & 2,85 & 0,0063 \\
Idade & 61,646 & 37,291 & 1,65 & 0,1043 \\
Grupo CONTROLE & $-1075,884$ & 368,433 & $-2,92$ & $0,0052^{*}$
\end{tabular}

"significância para $\mathrm{p}<0,05 ; \mathrm{MD}=$ desvio médio em dB; $\mathrm{AVCC}=$ melhor acuidade visual corrigida; DP= desvio padrão.

Analisando a potencial relação entre dados perimétricos e o desempenho na tarefa de busca visual, tornou-se interessante testar eventuais correlações entre dados globais e espaciais relacionados a essas variáveis. Observou-se que o MD e o TIG de busca visual apresentaram correlação significativa em ambos os grupos (GPAA: $r=-0,45 ; p=0,01$ vs CONTROLE: $r=0,37 ; p=0,049$ ). 
A sensibilidade média de três áreas periféricas da PV apresentaram correlações significativas com o tempo individual de busca nas regiões espaciais correspondentes, exceto na área PST $(r=-0,35 ; p=0,06)$. Não houve correlação significativa para nenhuma dessas áreas da PV no grupo CONTROLE, à exceção também da área PST ( $r=0,43 ; p=0,02)$ (Tabela 7).

Tabela 7 - Correlações entre os resultados de tempo individual de busca visual e parâmetros da PV, globais e organizados por áreas espaciais correspondentes

\begin{tabular}{llcccc}
\hline & & \multicolumn{2}{c}{ GPAA } & \multicolumn{2}{c}{ CONTROLE } \\
\hline \multicolumn{1}{c}{ Campo Visual } & \multicolumn{1}{c}{ Busca Visual } & r & $\mathbf{p}$ & $\mathbf{r}$ & $\mathbf{p}$ \\
\hline MD(dB) & Média Tempo Individual Global(s) & $-0,45$ & 0,01 & $+0,37$ & 0,049 \\
Média TD CEN(dB) & Média Tempo Individual CEN(s) & $-0,29$ & 0,12 & $+0,00$ & 0,99 \\
Média TD PIN(dB) & Média Tempo Individual PIN(s) & $-0,41$ & 0,03 & $+0,04$ & 0,84 \\
Média TD PSN(dB) & Média Tempo Individual PSN(s) & $-0,50$ & 0,006 & $-0,09$ & 0,65 \\
Média TD PIT(dB) & Média Tempo Individual PIT(s) & $-0,44$ & 0,016 & $+0,07$ & 0,71 \\
Média TD PST(dB) & Média Tempo Individual PST(s) & $-0,35$ & 0,06 & $+0,43$ & 0,02
\end{tabular}

MD= média dos desvios de sensibilidade do grupo; TD CEN= sensibilidade da área central do grupo; TD PIN= sensibilidade da área periférica ínfero-nasal; TD PSN= sensibilidade da área periférica supero-nasal; TD PIT= sensibilidade da área periférica ínfero-temporal; TD PST= sensibilidade da área periférica supero-temporal. Média Tempo Individual= média de tempo gasto para identificação de cada alvo entre as nove telas do exame, em segundos; Global= área global (abrangendo as cinco áreas da tela); $\mathrm{CEN}=$ área central; $\mathrm{PIN}=$ área periférica ínfero-nasal; $\mathrm{PSN}=$ área periférica supero-nasal; $\mathrm{PIT}=$ área periférica ínfero-temporal; PST= área periférica supero-temporal.

A Figura 12 apresenta o exemplo de um paciente do Grupo GPAA, no qual os gráficos observados no impresso da PV demonstram escotomas localizados, principalmente no quadrante nasal superior, espacialmente relacionados às áreas de maior TIG médio de busca visual. 
Figura 12 - Representação gráfica do exame de PV de um paciente do grupo GPAA e a distribuição espacial dos tempos individuais de busca dos estímulos visuais em diversas áreas da tela do programa Four. (A) gráfico pattern deviation; (B) gráfico perimétrico em escala de cinza; (C) gráfico total deviation; (D) gráfico demonstrando o tempo de busca de cada alvo nas nove telas, estando o diâmetro e a cor dos círculos representados de modo diretamente proporcional ao tempo gasto para determinação de cada estímulo. Nota-se boa correlação entre os maiores círculos no gráfico de busca visual e áreas de escotomas predominando no quadrante nasal superior da PV, ultrapassando discretamente as linhas horizontais e verticais.
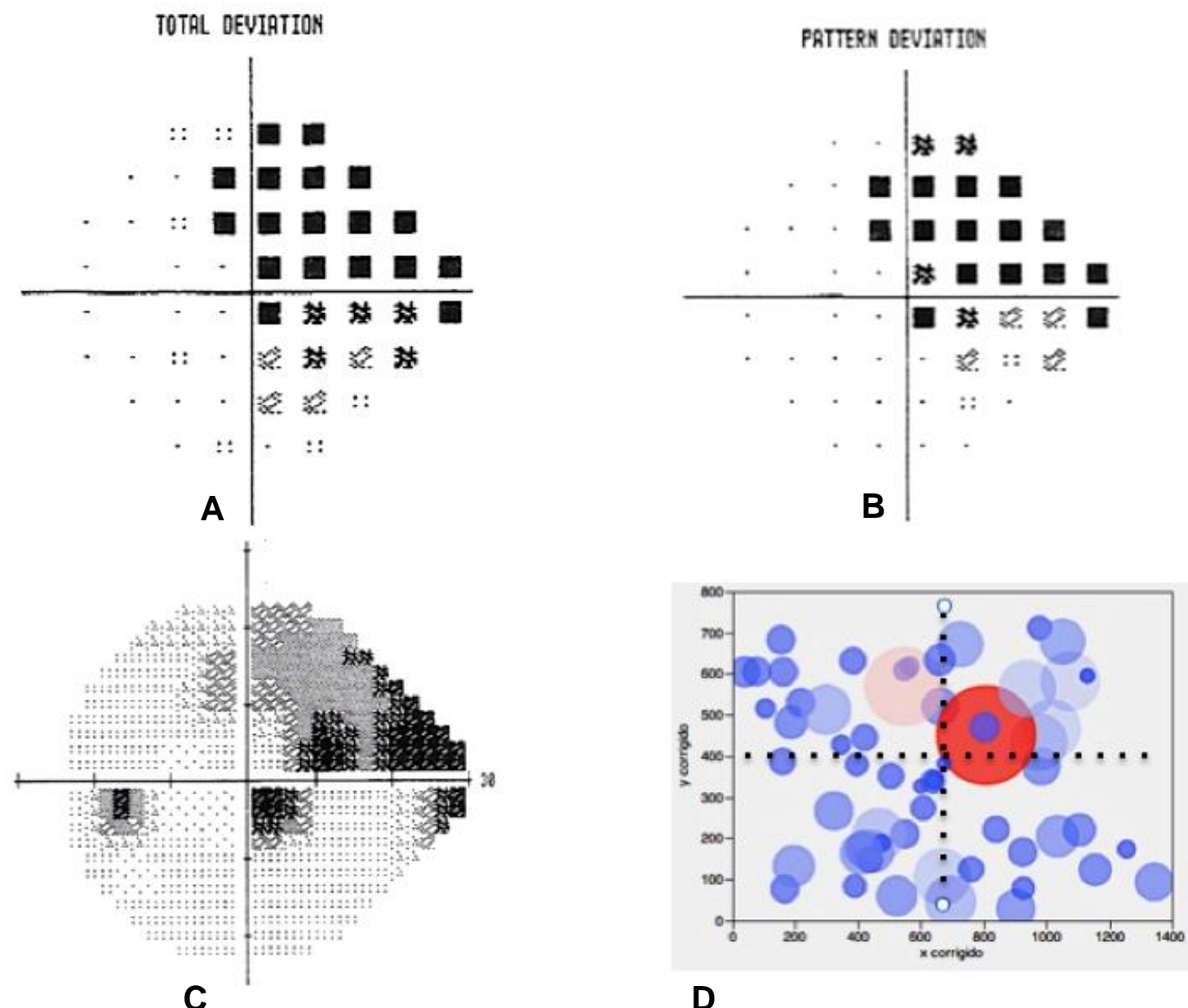

D 
5. Discussão 
A busca visual é uma complexa interação entre motricidade ocular, percepção visual, fatores cognitivos e plasticidade do sistema nervoso central (119). Uma boa capacidade de realização de busca visual favorece a execução de grande parte dos afazeres diários, como por exemplo, na procura de um objeto num armário, de um alimento na prateleira do supermercado ou de um rosto conhecido $(39,42,105,111,112)$. Perdas visuais podem comprometer a capacidade de busca visual do indivíduo $(30,61,104,105,120)$, podendo deixá-lo limitado em diversas atividades cotidianas. Assim, justifica-se investigar mecanismos que auxiliem no reconhecimento de perdas visuais e na piora no desempenho de busca visual.

Cinco estudos realizados exclusivamente em adultos e publicados entre 2011 e $2014(60,75-77,105)$ relataram associação entre dano glaucomatoso e deficiência em busca visual. Nesses, a leitura foi usada como a tarefa exigida de busca visual com significativa dificuldade para os pacientes com perda perimétrica glaucomatosa. Três estudos utilizaram o rastreador ocular para monitorar e registrar os movimentos oculares durante os testes de busca visual (75-77). Os pacientes com glaucoma apresentaram desempenho de busca visual significativamente pior, caracterizados por: menor tempo de fixação, maior número de movimentos sacádicos de regressão e menor número de movimentos sacádicos assertivos $(75-77,105)$. O maior número de sacádicos de regressão e a inadequada coordenação dos movimentos sacádicos foram diretamente proporcionais ao dano glaucomatoso (77), sendo que a amplitude dos movimentos sacádicos foi semelhante para os grupos controle e glaucomatoso (76). A análise do padrão dos movimentos oculares numa tarefa de busca visual, de modo semelhante à realizada no presente estudo, poderia corroborar para o entendimento quanto ao comportamento da busca visual. Assim, sugere-se que o sistema de rastreamento ocular seja utilizado em estudos futuros, devido à sua importância diagnóstica.

Autores que se basearam no tempo médio de busca visual em pacientes com glaucoma e indivíduos normais, na identificação de objetos em fotografias de cenas do cotidiano, observaram que esse tempo foi estatisticamente maior nos doentes. No entanto, o tempo de busca num quadro de símbolos, com diferentes 
intensidades de contraste (usando optotipos Landolt C), não apresentou diferença significativa. Também apontaram evidências de que a sensibilidade ao contraste e a resultados da PV apresentaram níveis de equivalência e associação com o tempo de busca dos pacientes com glaucoma, principalmente naqueles com idade avançada. Concluíram que indivíduos com defeito perimétrico em ambos os olhos foram mais lentos em localizar objetos em fotografias de cenas cotidianas, quando comparados a indivíduos saudáveis da mesma idade, mas não revelaram diferenças quanto ao tempo de busca quando o alvo era representado por símbolos $(60,104,105,111)$.

A avaliação dos movimentos oculares em pacientes glaucomatosos pode fornecer informações sobre o déficit funcional no glaucoma $(60,76,105)$. Defeitos perimétricos variados representam áreas no espaço que prejudicam a visão, tanto pela privação direta de informações do meio ambiente quanto pela redução da capacidade do sistema visual em programar movimentos sacádicos coordenados e eficientes em tarefas de busca visual (22). Pacientes com glaucoma e defeitos perimétricos em ambos os olhos mostraram maior dificuldade e menor agilidade na localização de imagens em fotografias de cenas cotidianas, quando comparados a indivíduos não glaucomatosos e sem defeitos perimétricos, da mesma idade (71,105). Jampel et. al. (2011) (107) encontraram diferença significativa no tempo de busca visual entre os grupos de pacientes glaucomatosos e controles quando utilizaram alvos numéricos numa tela digital. Esses resultados, assim como alguns deste estudo reforçam a hipótese de que pacientes glaucomatosos com perda perimétrica apresentam menor desempenho de busca visual.

No presente estudo, comparando dados de sensibilidade da PV, constatouse que o grupo GPAA apresentou, além de maior tempo de busca, valores de MD e PSD significativamente piores, do que o grupo CONTROLE. Smith, Glen e Crabb (2012) (14) apontaram evidências de que a sensibilidade ao contraste e a perimetria visual obtiveram níveis de equivalência e associação com o tempo de busca visual dos pacientes glaucomatosos, e que este tempo aumentaria ainda mais com a idade avançada. Foi observado, ainda, que no grupo GPAA, indivíduos com MD mais negativos demonstraram pior desempenho no exame de 
busca visual, representado pelo maior tempo de busca dos estímulos visuais. Em outro estudo (105), encontraram diferenças na movimentação ocular de pacientes glaucomatosos com perda perimétrica bilateral, quando comparados ao comportamento do grupo controle, durante uma tarefa de busca visual em fotografias de cenas do cotidiano, e verificaram que o grupo com glaucoma apresentou redução significativa da média de movimentos sacádicos em comparação com o grupo controle, o que pode indicar associação direta entre gravidade da perda estrutural e desempenho funcional.

De modo inovador, o presente estudo demonstrou pior desempenho funcional na tarefa de busca visual proposta, não só na comparação de parâmetros globais, mas também de outros propostos para análise da correspondência espacial com áreas de escotomas em pacientes com glaucoma. No grupo GPAA, a sensibilidade média de três das quatro áreas perimétricas periféricas apresentou correlação significativa com o tempo médio de busca visual na área correspondente da tela apresentada pelo programa Four (Tabela 5), o que sugere que nas áreas de perda perimétrica periférica, menores índices de sensibilidade estiveram relacionados ao maior tempo de busca nesses indivíduos. Já no grupo CONTROLE, tal correspondência não ocorreu, provavelmente por esse grupo não apresentar perdas perimétricas. $\mathrm{Na} P V$, o grupo GPAA apresentou áreas perimétricas periféricas mais afetadas do que a área central, bem como o tempo de busca visual nessas áreas foram maiores. Novamente indicando provável associação espacial direta entre o TD da perimetria visual e o tempo individual de busca visual na área correspondente, ou seja, áreas de maior perda perimétrica cursaram com pior desempenho na tarefa de busca visual (Tabela 4).

Wiecek et al. (2012) (78) avaliaram 17 adultos (dez pacientes com perda perimétrica periférica e sete sem perdas perimétricas) para verificar se defeitos perimétricos poderiam afetar os movimentos naturais de busca visual, de acordo com sua localização e extensão, após um período de treinamento visual realizado pelo grupo com perda perimétrica. No entanto, observaram que não houve diferença entre os grupos, fato em discrepância com os resultados do presente estudo. Especula-se que os resultados de Wieck et al. (78) podem ter sido 
influenciados pelo tamanho amostral não adequado, ou ainda, pelo efeito do treinamento, com o qual o paciente poderia aprender a realizar maior número de sacádicos para o lado da perda visual $(73,89,104,117)$, anulando eventuais diferenças relacionadas a perdas perimétricas. Tal efeito não se verifou neste estudo, uma vez que não foi realizado treinamento.

O desempenho da busca visual em cenas de ambiente podem ainda sofrer influência da visão parafoveal, uma vez que se acredita que a região foveal seria responsável pela visão de imagens projetadas dentro dos 2,5 graus centrais $(75,99,100,121)$. Assim, a natureza do alvo de teste seria importante no estudo de busca visual, uma vez que alvos maiores usariam áreas parafoveais para sua identificação e alvos centrais e menores, como os utilizados na leitura, teriam maior dependência da área foveal (98). No presente estudo, foram utilizados alvos maiores (5,5 minutos de arco) visando sua detecção por áreas visuais extrafoveais.

A acurácia da visão é naturalmente crescente em direção foveal. O movimento dos olhos é imprescindível para que o indivíduo possa trazer as informações para a região foveal e, assim, reconhecer os detalhes do ambiente. O modo como o indivíduo usa as informações e coordena os sacádicos de varredura pode fornecer indícios de sua capacidade de busca visual. Indivíduos com perdas perimétricas e desempenho prejudicado na busca visual, devido a lesões glaucomatosas, apresentaram padrão diferente de movimentos, com maior número de sacádicos e fixações na busca em cenas dinâmicas (76). Pesquisas sugerem que as perdas perimétricas mais acentuadas podem levar a restrições mais severas nos movimentos oculares, quando esses pacientes mostraram menor produção do número de sacadas e movimentos sacádicos de coordenação anômala (105). Este estudo aplicou alvos de maior exigência da visão foveal, fato que pode explicar, ao menos em parte, os resultados de maior associação dos tempos de busca com a sensibilidade das áreas perimétricas periféricas.

Um estímulo extrafoveal promove um sacádico para alinhamento deste com a fóvea e, assim, a presença de escotomas centrais contribuiria para a deteriorização dessa automação sacádica. Na leitura, a localização da fixação inicial (local de pouso) na palavra pode ser explicada com base nos cinco 
princípios de controle perceptuo-oculomotor, a saber: 1) cada palavra tem uma localização de pouso específica; 2) há um desvio sistemático da escala sacádica para o local de pouso em cada alvo; 3) há uma variação perceptuo-oculomotora como segunda fonte não sistemática de variação dos locais de pouso; 4) a variabilidade perceptuo-oculomotora aumenta com a distância do local de partida da busca; 5) o erro de intervalo sacádico tem redução em sacadas de maior distância (71,72,99,121). A frequência de fixação sobre uma palavra, imediatamente após a fixação inicial do olho sobre ela, varia de acordo com a sua localização. Ela é mais baixa perto do centro da palavra e acelera quando se distancia do centro. Se a frequência de fixação está relacionada com a frequência de identificação bem sucedida de uma palavra, uma única diferença de letra na localização de fixação em uma palavra pode fazer considerável diferença na probabilidade de fixação dessa palavra $(42,73,99,100)$. Visando minimizar as variações de frequência de fixação, como ocorre durante a leitura textual, 0 presente estudo utilizou dígitos individuais dispostos aleatoriamente na tela para busca visual e sem variação em suas dimensões. Não foi observada diferença significativa na comparação da sensibilidade visual da área CEN em ambos os grupos. Uma vez que esta região não apresentou perdas perimétricas em ambos os grupos, sugere-se que áreas sem perdas na PV não apresentariam diferenças no tempo de busca visual na região correlacionada.

Apesar dos rígidos critérios de inclusão e exclusão, que visaram minimizar os fatores influenciadores oculares e cognitivos dos processos envolvidos na busca visual, algumas limitações podem ser observadas neste estudo. Objetivouse realizar um teste de busca visual com condições de reprodução, repetição e monitoramento padronizado por meio de uma plataforma digital, criada a partir de conceitos e recursos utilizados em outros experimentos, com adaptações, quando necessárias. Assim, realizou-se o teste com uniformização da exposição ao alvo, a saber: tamanho, contraste, localização " $x, y$ ”, tempos e forma de acesso e coleta dos dados). Essa plataforma, no entanto, ficou limitada ao uso do mouse para a execução da tarefa, que exige mínima coordenação e experiência específica para seu manejo. A falta de uniformização quanto à familiaridade com o uso do mouse e/ou coordenação motora manual fina imprecisa, poderiam ter influenciado no 
desempenho do examinado, principalmente pela inclusão de idosos, gerando eventuais vieses metodológicos. Contudo, considerando os resultados da análise de covariância, observou-se que o tempo individual de busca visual não deve ter sido influenciado pela idade, neste grupo de sujeitos. De qualquer maneira, sugere-se a busca de plataformas de busca visual, cujo mecanismo de resposta seja independente da coordenação motora manual relacionada ao uso do mouse ou cursor gráfico.

Inúmeros recursos para o diagnóstico, seguimento e manejo do glaucoma, tais como os exames perimétricos, permitem uma avaliação mais sensível e refinada da função visual por meio de dispositivos computadorizados. A monitoração e análise das características da busca visual numa tarefa padronizada e automatizada poderia, então, ser capaz de identificar indícios característicos em casos de indivíduos com glaucoma inicial, dentre aqueles suspeitos da doença $(112,113)$. Nesse sentido, várias aplicações podem ser elencadas no desenvolvimento de instrumentos voltados à avaliação do desempenho em tarefas de busca visual em indivíduos com problemas visuais, seja no treinamento de auxílio ao desenvolvimento adaptativo compensatório da perda de campo visual, na identificação precoce da evolução do dano glaucomatoso, ou na otimização da visão no campo remanescente.

Neste estudo, áreas de defeito perimétrico evidenciaram associação com maior tempo de busca de alvos presentes em regiões perimétricas periféricas, em pacientes glaucomatosos com boa acuidade visual, ou seja, observou-se que perdas perimétricas periféricas de sujeitos com glaucoma podem influenciar negativamente no desempenho de busca visual, devido ao aumento do tempo de busca nessas regiões. A incidência de acidentes automobilísticos, industriais, domésticos, além de maior dependência pessoal de portadores de deficiências visuais, pode estar associada ao pior desempenho de busca visual em sujeitos que apresentam perda perimétrica periférica.

A ciência poderá se expandir em busca do esclarecimento dos mecanismos envolvidos na complexa interação entre o sistema visual e o desempenho nas atividades cotidianas, em prol do bem estar humano. 
6. Conclusões 
Após análise dos resultados, concluiu-se que:

- Pacientes com GPAA e acuidade visual normal apresentaram tempo significativamente maior (aproximadamente o dobro) para execução da tarefa de busca visual em plataforma digital computadorizada que os sujeitos controles.

- O tempo individual de busca visual para cada alvo do teste, em ambos os grupos, apresentou correlação significativa com a AVCC e o diagnóstico de GPAA.

- Os pacientes do grupo GPAA mostraram correlação espacial direta e proporcional entre a intensidade das perdas perimétricas periféricas e o tempo de busca visual nas regiões correspondentes dessas perdas, com exceção da região temporal superior. Não houve diferença significativa no tempo de busca visual nas áreas centrais da perimetria visual de ambos os grupos. 


\section{Referências Bibliográficas}

${ }^{1}$ Elaboradas de acordo com as Diretrizes para Apresentação de Dissertações e Teses da USP: Documento Eletrônico e Impresso - Parte IV (Vancouver) 3를 ed. São Paulo: SIBi/USP, 2016. 
1. Tsatsos M, Broadway D. Controversies in the history of glaucoma: is it all a load of old Greek? Br J Ophthalmol. 2007;91(11):1561-2.

2. Vogel WH, Berke A. Brief history of vision and ocular medicine. Amsterdam: Kugler Publications; 2009. 263p.

3. Hipocrates, Verhoofd L, Marks E. The aphorisms of Hippocrates. New York: Collins \& Co. 1817. 186p. Disponível em: https://archive.org/details/aphorismsofhippo00hipp. Acesso em 30 março 2017.

4. Fronimopoulos J, Lascaratos J. The terms glaucoma and cataract in the ancient Greek and Byzantine writers. Doc Ophthalmol. 1991;77(4):369-75.

5. Preston T. Two Letters from Mr. Thomas Preston to Mr. Joseph Ames, F. R. S. concerning the Island of Zetland. V. 43. Philosophical Transaction, 1744. 9p. Disponível em: https://archive.org/details/jstor-104427. Acesso em 05 abril 2017

6. James RR, Sorsby A. RICHARD BANISTER: Additional facts in relation to the Father of British Ophthalmology. Br J Ophthalmol. 1934;18(3):156-9.

7. de Saint-Yves C. Nouveau traité des maladies des yeux, les remedes qui y conviennent, \& les operations de chirurgie. Paris: Pierre-Augustin Lemercier; 1722. p. 264-70.

8. Goldmann H. Albrecht von Graefe and glaucoma. Albrecht Von Graefes Arch Klin Exp Ophthalmol. 1971;181(2):94-106.

9. Duke-Elder S, Jay B. Diseases of the lens and vitreous; glaucoma and hypotony. In: System of ophthalmology. V. 11. London: H. Kimpton. 1969. p. 105.

10. Tan SY, Zia JK. Albrecht von Graefe (1828-1870): founder of scientific ophthalmology. Singapore Med J. 2007;48(9):797-8.

11. Curran E. A new operation for glaucoma involving a new principle in the aetiology and treatment of chronic primary glaucoma. Arch Ophthalmol. 1920;49:131-55.

12. Shields MB. Cyclodestructive surgery for glaucoma: past, present, and future. Trans Am Ophthalmol Soc. 1985;83:285-303.

13. Barkan O. Glaucoma: classification, causes, and surgical control*. Am J Ophthalmol. 1938;21(10):1099-117.

14. Smith ND, Glen FC, Crabb DP. Eye movements during visual search in patients with glaucoma. BMC Ophthalmol. 2012;12:45. 
15. Resnikoff $S$ et al. Global data on visual impairment in the year 2002. Bull World Health Organ. 2004;82(11):844-51.

16. Who. Consultation on development of standards for characterization of vision loss. Prev Blind Deaf. 2003;(September):4-5.

17. Tham Y-C et al. Global Prevalence of Glaucoma and Projections of Glaucoma Burden through 2040. Ophthalmology. 2014;121(11):2081-90.

18. Quigley HA, Broman AT. The number of people with glaucoma worldwide in 2010 and 2020. Br J Ophthalmol. 2006;90(3):262-7.

19. Quigley HA. Number of people with glaucoma worldwide. Br J Ophthalmol. 1996;80(5):389-93.

20. Pascolini D et al. 2002 global update of available data on visual impairment: a compilation of population-based prevalence studies. Ophthalmic Epidemiol. 2004;11(2):67-115.

21. McKean-Cowdin $R$ et al. Impact of Visual Field Loss on Health-Related Quality of Life in Glaucoma. Ophthalmology. 2008;115(6):941-948.e1.

22. Hattenhauer MG et al. The probability of blindness from open-angle glaucoma. Ophthalmology. 1998;105(11):2099-104.

23. Klein BE et al. Prevalence of glaucoma. The Beaver Dam Eye Study. Ophthalmology. 1992;99(10):1499-504.

24. Coffey $\mathrm{M}$ et al. Prevalence of glaucoma in the west of Ireland. $\mathrm{Br} \mathrm{J}$ Ophthalmol. 1993;77(1):17-21.

25. Tielsch JM et al. A population-based evaluation of glaucoma screening: the Baltimore Eye Survey. Am J Epidemiol. 1991;134(10):1102-10.

26. Sommer A et al. Racial differences in the cause-specific prevalence of blindness in east Baltimore. N Engl J Med. 1991;325(20):1412-7.

27. Weinreb RN, Khaw PT. Primary open-angle glaucoma. Lancet. 2004;363(9422):1711-20.

28. Weinreb RN, Aung T, Medeiros FA. The Pathophysiology and Treatment of Glaucoma. JAMA. 2014;311(18):1901.

29. Mills RP et al. Categorizing the stage of glaucoma from pre-diagnosis to endstage disease. Am J Ophthalmol. 2006;141(1):24-30.

30. Ramulu P. Glaucoma and disability: which tasks are affected, and at what stage of disease? Curr Opin Ophthalmol. 2009;20(2):92-8. 
31. De Moraes CGV et al. Risk factors for visual field progression in treated glaucoma. Arch Ophthalmol. 2011;129(5):562-8. Erratum in Arch Ophthalmol. 2011;129(7):878.

32. Susanna R et al. Why Do People (Still) Go Blind from Glaucoma? Transl Vis Sci Technol. 2015;4(2):1.

33. Susanna R, Vessani RM. Staging glaucoma patient: why and how? Open Ophthalmol J. 2009;3(2):59-64.

34. Chen PP. Blindness in patients with treated open-angle glaucoma. Ophthalmology. 2003;110(4):726-33.

35. Quigley HA. Identification of glaucoma-related visual field abnormality with the screening protocol of frequency doubling technology. Am J Ophthalmol. 1998;125(6):819-29.

36. Grant WM, Burke JF. Why do some people go blind from glaucoma? Ophthalmology. 1982;89(9):991-8.

37. Dielemans I et al. The prevalence of primary open-angle glaucoma in a population-based study in The Netherlands. The Rotterdam Study. Ophthalmology. 1994;101(11):1851-5.

38. Mason RP et al. National survey of the prevalence and risk factors of glaucoma in St. Lucia, West Indies. Part I. Prevalence findings. Ophthalmology. 1989;96(9):1363-8.

39. Richman $\mathrm{J}$ et al. Relationships in glaucoma patients between standard vision tests, quality of life, and ability to perform daily activities. Ophthalmic Epidemiol. 2010;17(3):144-51.

40. Paula JS et al. Medical decision, persistence of initial treatment, and glaucoma progression in a Brazilian reference hospital. Arq Bras Oftalmol. 2010;73(2):141-5.

41. Bourne RRA et al. Number of people blind or visually impaired by glaucoma worldwide and in world regions 1990-2010: A meta-analysis. PLoS One. 2016;11(10):e0162229.

42. Crabb DP et al. How does glaucoma look?: patient perception of visual field loss. Ophthalmology. 2013;120(6):1120-6.

43. Hart WM, Becker B. The onset and evolution of glaucomatous visual field defects. Ophthalmology. 1982;89(3):268-79.

44. Mikelberg FS et al. Ability of the heidelberg retina tomograph to detect early glaucomatous visual field loss. J Glaucoma. 1995;4(4):242-7. 
45. Werner EB, Drance SM. Early visual field disturbances in glaucoma. Arch Ophthalmol. 1977;95(7):1173-5.

46. Hoffmann EM et al. Intereye spatial relationship of abnormal neuroretinal rim locations in glaucoma patients from the diagnostic innovations in glaucoma study. Am J Ophthalmol. 2007;143(5):781-7.

47. Sample PA et al. Identifying glaucomatous vision loss with visual-functionspecific perimetry in the diagnostic innovations in glaucoma study. Invest Ophthalmol Vis Sci. 2006;47(8):3381-9.

48. Harwerth RS et al. Linking structure and function in glaucoma. Prog Retin Eye Res. 2010;29(4):249-71.

49. Holopigian $\mathrm{K}$ et al. Electrophysiologic assessment of photoreceptor function in patients with primary open-angle glaucoma. J Glaucoma. 2000;9(2):163-8.

50. Pearson $\mathrm{P}$, Swanson $\mathrm{WH}$, Fellman RL. Chromatic and achromatic defects in patients with progressing glaucoma. Vision Res. 2001;41(9):1215-27.

51. Sample PA, Juang PS, Weinreb RN. Isolating the effects of primary openangle glaucoma on the contrast sensitivity function. Am $\mathrm{J}$ Ophthalmol. 1991;112(3):308-16.

52. Lin J-C, Yang M-C. Correlation of visual function with health-related quality of life in glaucoma patients. J Eval Clin Pract. 2010;16(1):134-40.

53. Friedman $\mathrm{C}$ et al. Association between higher order visual processing abilities and a history of motor vehicle collision involvement by drivers ages 70 and over. Investig Opthalmology Vis Sci. 2013;54(1):778-82.

54. Owsley C, McGwin G, Ball K. Vision impairment, eye disease, and injurious motor vehicle crashes in the elderly. Ophthalmic Epidemiol. 1998;5(2):10113.

55. Gupta N, Yücel YH. Glaucoma as a neurodegenerative disease. Curr Opin Ophthalmol. 2007;18(2):110-4.

56. Quigley HA et al. The prevalence of glaucoma in a population-based study of Hispanic subjects: Proyecto VER. Arch Ophthalmol. 2001;119(12):1819-26.

57. Yücel $\mathrm{YH}$ et al. Memantine protects neurons from shrinkage in the lateral geniculate nucleus in experimental glaucoma. Arch Ophthalmol. 2006;124(2):217-25.

58. Varma R et al. Impact of severity and bilaterality of visual impairment on health-related quality of life. Ophthalmology. 2006;113(10):1846-53. 
59. Green J, Siddall H, Murdoch I. Learning to live with glaucoma: a qualitative study of diagnosis and the impact of sight loss. Soc Sci Med. 2002;55(2):257-67.

60. Smith ND, Crabb DP, Garway-Heath DF. An exploratory study of visual search performance in glaucoma. Ophthalmic Physiol Opt. 2011;31(3):22532.

61. Glen FC, Crabb DP, Garway-Heath DF. The direction of research into visual disability and quality of life in glaucoma. BMC Ophthalmol. 2011;11(1):19.

62. Plude DJ, Hoyer WJ, Lazar J. Age, response complexity, and target consistency in visual search. Exp Aging Res. 1982;8(2):99-102.

63. MacKeben M, Fletcher DC. Target search and identification performance in low vision patients. Investig Ophthalmol Vis Sci. 2011;52(10):7603-9.

64. Mort DJ et al. Differential cortical activation during voluntary and reflexive saccades in man. Neuroimage. 2003;18(2):231-46.

65. Luo G, Satgunam P, Peli E. Visual search performance of patients with vision impairment: effect of JPEG image enhancement. Ophthalmic Physiol Opt. 2012;32(5):421-8.

66. Møller F, Laursen ML, Sjølie AK. The contribution of microsaccades and drifts in the maintenance of binocular steady fixation. Graefes Arch Clin Exp Ophthalmol. 2006;244(4):465-71.

67. Nachmias J. Two-dimensional motion of the retinal image during monocular fixation. J Opt Soc Am. 1959;49:901-8.

68. Nachmias J. Determiners of the drift of the eye during monocular fixation. $J$ Opt Soc Am. 1961;51:761-6.

69. Steinman RM et al. Miniature eye movement. Science. 1973;181(4102):8109.

70. Bullimore MA, Bailey IL. Reading and eye movements in age-related maculopathy. Optom Vis Sci. 1995;72(2):125-38.

71. Rayner $\mathrm{K}$ et al. Eye movements and word skipping during reading: Effects of word length and predictability. J Exp Psychol Hum Percept Perform. $2011 ; 37(2): 514-28$.

72. Rayner K, Fischer MH, Pollatsek A. Unspaced text interferes with both word identification and eye movement control. Vision Res. 1998 Apr;38(8):112944. 
73. Whittaker SG, Budd J, Cummings RW. Eccentric fixation with macular scotoma. Invest Ophthalmol Vis Sci. 1988;29(2):268-78.

74. Evans KK et al. Visual attention. Wiley Interdiscip Rev Cogn Sci. $2011 ; 2(5): 503-14$.

75. Burton R, Smith ND, Crabb DP. Eye movements and reading in glaucoma: observations on patients with advanced visual field loss. Graefes Arch Clin Exp Ophthalmol. 2014;252(10):1621-30.

76. Crabb DP et al. Exploring eye movements in patients with glaucoma when viewing a driving scene. PLoS One. 2010;5(3):e9710.

77. Smith ND et al. Using eye tracking to assess reading performance in patients with glaucoma: a within-person study. J Ophthalmol. 2014;2014:120528.

78. Wiecek $\mathrm{E}$ et al. Effects of peripheral visual field loss on eye movements during visual search. Front Psychol. 2012;3:472.

79. Lowe J, Drasdo N. Patients' responses to retinitis pigmentosa. Optom Vis Sci. 1992;69(3):182-5.

80. Beasley IG, Davies LN. The effect of spectral filters on reading speed and accuracy following stroke. J Optom. 2013;6(3):134-40.

81. Warren M. Pilot study on activities of daily living limitations in adults with hemianopsia. Am J Occup Ther. 2009;63(5):626-33.

82. Kerkhoff G, Münssinger U, Meier EK. Neurovisual rehabilitation in cerebral blindness. Arch Neurol. 1994;51(5):474-81.

83. Rowe FJ et al. A prospective profile of visual field loss following stroke: prevalence, type, rehabilitation, and outcome. Biomed Res Int. 2013;2013:719096.

84. Cornelissen FW, Bruin KJ, Kooijman AC. The influence of artificial scotomas on eye movements during visual search. Optom Vis Sci Off Publ Am Acad Optom. 2005;82(1):27-35.

85. Humphrey DG, Kramer AF. Age differences in visual search for feature, conjunction, and triple-conjunction targets. Psychol Aging. 1997;12(4):70417.

86. Mort DJ, Kennard C. Visual search and its disorders. Curr Opin Neurol. 2003;16(1):51-7.

87. Hayhoe M, Ballard D. Eye movements in natural behavior. Trends Cogn Sci. 2005;9(4):188-94. 
88. Rothkopf CA, Ballard DH, Hayhoe MM. Task and context determine where you look. J Vis. 2007;7(14):16.1-20

89. Roth $T$ et al. Comparing explorative saccade and flicker training in hemianopia: a randomized controlled study. Neurology. 2009;72(4):324-31.

90. Pflugshaupt $\mathrm{T}$ et al. Linking physiology with behaviour: Functional specialisation of the visual field is reflected in gaze patterns during visual search. Vision Res [Internet]. 2009;49(2):237-48.

91. Boucart $M$ et al. Finding faces, animals, and vehicles in far peripheral vision. J Vis. 2016;16(2):10.

92. Millodot M, Lamont A. Colour vision deficiencies in French Canadian school children. Can J Public Health. 1974;65(6):461-2.

93. Chanceaux $\mathrm{M}$ et al. Word processing speed in peripheral vision measured with a saccadic choice task. Vision Res. 2012;56:10-9.

94. Velisavljević L, Elder JH. Visual short-term memory of local information in briefly viewed natural scenes: Configural and non-configural factors. J Vis. 2008;8(16):8.1-17.

95. Larson AM, Loschky LC. The contributions of central versus peripheral vision to scene gist recognition. J Vis. 2009;9(10):6-6.

96. Kwon M, Legge GE. Spatial-frequency cutoff requirements for pattern recognition in central and peripheral vision. Vision Res. 2011;51(18):19952007.

97. Westheimer $\mathrm{G}$. The spatial grain of the perifoveal visual field. Vision Res. 1982;22(1):157-62.

98. Hess RF, Jacobs RJ, Vingrys A. Central versus peripheral vision: evaluation of the residual function resulting from a uniocular macular scotoma. Am J Optom Physiol Opt. 1978;55(9):610-4.

99. McConkie GW et al. Eye movement control during reading: I. The location of initial eye fixations on words. Vision Res. 1988;28(10):1107-18.

100. McConkie GW et al. Eye movement control during reading: II. Frequency of refixating a word. Percept Psychophys. 1989;46(3):245-53.

101. Viswanathan $A C$ et al. Severity and stability of glaucoma: patient perception compared with objective measurement. Arch Ophthalmol (Chicago, III 1960). $1999 ; 117(4): 450-4$. 
102. Coeckelbergh TRM et al. The effect of visual field defects on eye movements and practical fitness to drive. Vision Res. 2002;42(5):669-77.

103. Coeckelbergh TRM et al. The effect of visual field defects on driving performance: a driving simulator study. Arch Ophthalmol. 2002;120(11):1509-16.

104. Glen FC, Smith ND, Crabb DP. Saccadic eye movements and face recognition performance in patients with central glaucomatous visual field defects. Vision Res. 2013;82:42-51.

105. Smith ND et al. Eye movements in patients with glaucoma when viewing images of everyday scenes. Seeing Perceiving. 2012;25(5):471-92.

106. Lorenzana L et al. A New Method of Assessing Ability to Perform Activities of Daily Living: Design, Methods and Baseline Data. Ophthalmic Epidemiol. 2009;16(2):107-14.

107. Jampel HD et al. Assessment of visual function in glaucoma: a report by the American Academy of Ophthalmology. Ophthalmology. 2011;18(5):986-1002.

108. Hu CX et al. What do patients with glaucoma see? Visual symptoms reported by patients with glaucoma. Am J Med Sci. 2014;348(5):403-9.

109. McKean-Cowdin R et al. Severity of visual field loss and health-related quality of life. Am J Ophthalmol. 2007;143(6):1013-23.

110. McKean-Cowdin $R$ et al. Longitudinal changes in visual acuity and healthrelated quality of life: the Los Angeles Latino Eye study. Ophthalmology. 2010;117(10):1900-7, 1907.e1.

111. Glen FC et al. Do patients with glaucoma have difficulty recognizing faces? Investig Ophthalmol Vis Sci. 2012;53(7):3629-37.

112. Loughman J, Davison $\mathrm{P}$, Flitcroft I. Open angle glaucoma effects on preattentive visual search efficiency for flicker, motion displacement and orientation pop-out tasks. Br J Ophthalmol. 2007;91(11):1493-8.

113. Loughman J, Davison P, Flitcroft I. Diagnostic Sensitivity/Specificity of Preattentive Vision Tests in Glaucoma. Optom Vis Sci. 2008;85(7):543-6.

114. Burton $\mathrm{R}$ et al. Glaucoma and reading: exploring the effects of contrast lowering of text. Optom Vis Sci. 2012;89(9):1282-7.

115. Ball $\mathrm{K}$ et al. Visual attention problems as a predictor of vehicle crashes in older drivers. Invest Ophthalmol Vis Sci. 1993;34(11):3110-23. 
116. Schimiti RB et al. Full-threshold versus Swedish Interactive Threshold Algorithm (SITA) in normal individuals undergoing automated perimetry for the first time. Ophthalmology. 2002;109(11):2084-92; discussion 2092.

117. Katz J, Sommer A, Witt K. Reliability of visual field results over repeated testing. Ophthalmology. 1991;98(1):70-5.

118. Bickler-Bluth $M$ et al. Assessing the utility of reliability indices for automated visual fields. Testing ocular hypertensives. Ophthalmology. 1989;96(5):616-9.

119. Bertera JH, Rayner K. Eye movements and the span of the effective stimulus in visual search. Percept Psychophys. 2000;62(3):576-85.

120. Ramulu PY. Glaucoma and Reading Speed. Arch Ophthalmol. $2009 ; 127(1): 82$.

121. McConkie GW, Currie CB. Visual stability across saccades while viewing complex pictures. J Exp Psychol Hum Percept Perform. 1996;22(3):563-81. 
8. Anexos 


\section{ANEXO A}

\section{COMPROVANTE DE APROVAÇÃO DO COMITÊ DE ÉTICA}

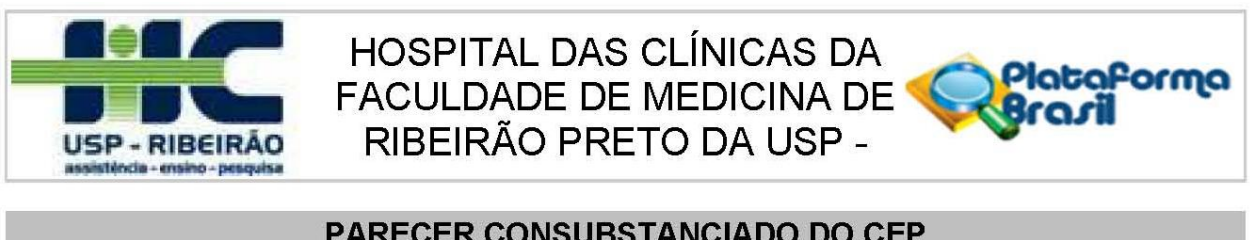

\section{DADOS DO PROJETO DE PESQUISA}

Titulo da Pesquisa: CARACTERÍSTICA DOS MOVIMENTOS SACÁDICOS OCULARES DURANTE BUSCA VISUAL PADRONIZADA EM PACIENTES COM GLAUCOMA

Pesquisador: CASSIA SENGER

Área Temática:

Versão: 1

CAAE: 30816414.1 .0000 .5440

Instituição Proponente: Hospital das Clínicas da Faculdade de Medicina de Ribeirão Preto da USP -

Patrocinador Principal: Financiamento Próprio

\section{DADOS DO PARECER}

Número do Parecer: 660.663

Data da Relatoria: $21 / 05 / 2014$

\section{Apresentação do Projeto:}

Trata-se de estudo transversal, não-randomizado, em uma única instituição, no qual se fará uma análise comparativa sobre o desempenho em teste computadorizado de busca visual entre pacientes glaucomatosos e um grupo controle de pacientes sem glaucoma. A maioria dos dados analisados já foi obtida, porém os indivíduos selecionados para participar da pesquisa, 40 (20 no grupo controle e 20 no grupo com glaucoma) serão submetidos ao procedimento busca visual computadorizada, de caráter não invasivo e sem efeitos colaterais para os indivíduos participantes.

\section{Objetivo da Pesquisa:}

O objetivo geral da pesquisa é comparar o movimento de busca visual por meio da análise da característica dos movimentos sacádicos oculares em indivíduos normais e pacientes glaucomatosos. Como objetivos específicos avaliar o tempo de resposta, número de fixações e o padrão de deslocamento sacádico anterior à fixação durante o procedimento de busca visual computadorizada.

\section{Avaliação dos Riscos e Benefícios:}

Nosso trabalho de pesquisa não implica, gera ou se associa a qualquer risco aos participantes, pois não há qualquer aplicação ou alteração do uso de qualquer medicação tópica ou não; não haverá administração de drogas, realização de procedimentos ou alteração do estado próprio do

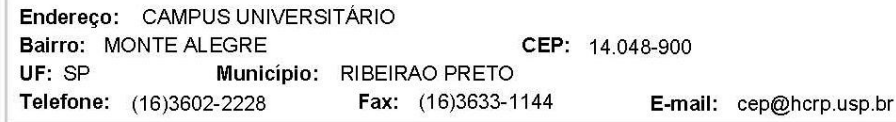




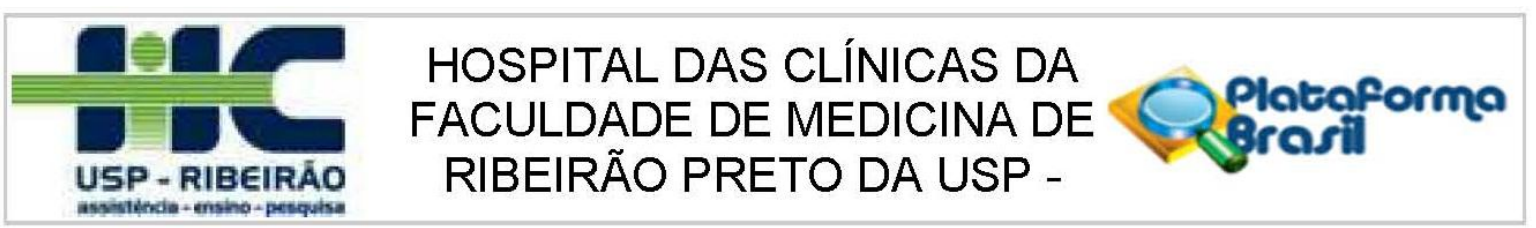

Continuação do Parecer: 660.663

paciente; sendo somente utilizado os dados referentes aos exames já realizados rotineiramente no serviço para estes pacientes, para serem

estudados e confrontados ao fim do trabalho; além de submete-los ao teste de busca visual frente ao alvo apresentado. O Glaucoma é uma doença que acomete grande parte da população, implicando em perdas funcionais e da qualidade de vida aos seus portadores. O conhecimento e o entendimento adequado das características das lesões glaucomatosas são de grande auxílio científico na busca da minimização e/ou prevenção dos danos irreversíveis inerentes à essa patologia, que é responsável por um alto custo social e econômico da

humanidade.

\section{Comentários e Considerações sobre a Pesquisa:}

O projeto de pesquisa está bem escrito, com metodologia clara e concisa. A equipe de pesquisadores possui experiência acumulada para realização do projeto e não há erros metodológicos ou de programação que possam comprometer o projeto. Os equipamentos necessários para realização dos testes e procedimentos propostos estão disponíveis na instituição e também não representam óbice a sua realização. não há exames ou procedimentos invasivos ou que coloquem em risco a saúde dos pacientes.

\section{Considerações sobre os Termos de apresentação obrigatória:}

Foram anexados novas versões dos documentos.

\section{Recomendações:}

Não há.

\section{Conclusões ou Pendências e Lista de Inadequações:}

O CEP considera o Projeto de Pesquisa (Versão 2 de 20/05/2014) e o Termo de Consentimento Livre e Esclarecido (Versão 2 de 20/05/2014) aprovados.

\section{Situação do Parecer:}

Aprovado

\section{Necessita Apreciação da CONEP:}

Não

\section{Considerações Finais a critério do CEP:}

Projeto Aprovado: Tendo em vista a legislação vigente, devem ser encaminhados ao CEP, relatórios parciais anuais referentes ao andamento da pesquisa e relatório final ao término do trabalho. Qualquer modificação do projeto original deve ser apresentada a este CEP em nova versão, de forma objetiva e com justificativas, para nova apreciação.

Endereço: CAMPUS UNIVERSITÁRIO

Bairro: MONTE ALEGRE CEP: $14.048-900$

UF: SP Município: RIBEIRAO PRETO

Telefone: (16)3602-2228 Fax: (16)3633-1144 E-mail: cep@hcrp.usp.br 


\section{ANEXO B}

\section{TERMO DE CONSENTIMENTO LIVRE E ESCLARECIDO}

Você está sendo convidado(a) como voluntário(a) a participar da pesquisa:

\section{Característica dos movimentos sacádicos oculares durante busca visual padronizada em pacientes com glaucoma}

Pesquisadores: Cássia Senger, Marcelo Jordão Lopes da Silva, André M V Messias e Jayter Silva de Paula

Após ser esclarecido(a) sobre as informações a seguir, no caso de aceitar fazer parte do estudo, assine ao final deste documento, que está em duas vias. Uma delas é sua e a outra do pesquisador responsável.

\section{Explicação da Justificativa e Objetivos do Estudo}

O glaucoma é uma doença ocular que em geral se manifesta por aumento da pressão do olho (pressão intraocular). Quando não tratada, esta pressão aumentada afeta a visão até causar cegueira. A doença leva a morte prematura de células da retina e nervo óptico e assim afeta a visão progressivamente até a perda total da capacidade de enxergar. É uma doença que normalmente não apresenta sintomas.

A visão nos ajuda em grande parte das nossas tarefas diárias. Para encontrarmos um objeto, ardarmos, reconhecermos um local ou determinado ambiente, lermos ou prepararmos nosso alimento, buscamos com nossa visão o quê nos interessa. Se a visão estiver boa, esse movimento ocular pode ser realizado com facilidade e agilidade, caso a visão esteja prejudicada esse movimento ocular poderá ser mais difícil ou não proveitoso na busca de uma determinada imagem.

É de interesse estudar, assim,como ocorre esse movimento de busca ocular durante a tarefa de encontrar objetos numa tela de computador, levando em conta diferenças entre pacientes glaucomatosos e pacientes sem glaucoma para melhorar o entendimento de como o glaucoma pode alterar a função de busca visual.

Esta pesquisa se justifica pela possibilidade de um maior conhecimento do modo como o glaucoma interfere na visão e na tarefa de encontrar objetos, para então, conhecer melhor a doença, auxiliar na elaboração de exames de diagnóstico mais rápido e, talvez, documentação da evolução do glaucoma.

\section{Explicando a participação no estudo}

Sua participação é voluntária. Não haverá compensação econômica ou financeira por sua participação nesse estudo, ou seja, não há previsão de nenhum ressarcimento de gastos referentes a transporte, alimentação e demais custos com despesas relacionados à sua participação, mas também você não terá gastos extras relativos aos procedimentos, exames e consultas médicas.

Durante o estudo você deverá comparecer às visitas de acompanhamento, conforme instruído pelo seu médico. Você poderá informar seu médico caso venha a usar qualquer outra medicação ocular.

Você pode abandonar o estudo quando quiser. Se decidir abandonar sua participação nesse estudo, isso não trará nenhuma consequência no tratamento que está fazendo com a equipe médica. 


\section{Explicando quanto a prováveis benefícios}

Este estudo vai utilizar os dados através da observação e filmagem do comportamento ocular durante a tarefa de busca visual, para encontrar a imagem de um determinado objeto, numa tela de computador, através da captação de imagens por uma câmera de vídeo adaptada na frente dos seus olhos, sem qualquer interferência ocular ou visual, temporária ou permanente a você.

Este estudo poderá fornecer informações que serão benéficas para 0 entendimento, a avaliação e o seguimento do glaucoma quanto à busca visual.

\section{Procedimentos: 0 que acontecerá se eu decidir participar?}

Você responderá algumas perguntas sobre os medicamentos que você utiliza atualmente e sobre os medicamentos que você já utilizou para tratar o glaucoma. Além disso, o médico irá questioná-lo sobre sua saúde e doenças que já foram tratadas. De posse destas respostas e após um exame clínico oftalmológico, o médico irá informar se você pode ou não pode participar do estudo. Assim que o médico autorizar a sua participação no estudo, ele irá pedir que leia atentamente e assine este Termo de Consentimento Livre e Esclarecido, irá Ihe entregar uma cópia do consentimento e irá realizar alguns exames em seus olhos.

Os procedimentos de exame ocorrerão no ambulatório de oftalmologia do Hospital das Clínicas de Ribeirão Preto.

\section{Explicando o acompanhamento e os exames oftalmológicos}

Todos os pacientes serão submetidos aos exames que seguem, todos não invasivos, não dolorosos e sem risco para sua saúde ocular.

O exame oftalmológico constará de: medida da acuidade visual, biomicoscopia, tonometria e fundoscopia.

Exames computadorizados: perimetria visual, retinografia e observação e filmagem durante a tarefa de buscar objetos padronizados.

Todos os pacientes serão examinados e filmados durante a execução da tarefa de procura de um determinado objeto projetado na tela de um computador.

Veja a seguir a explicação de como eles são realizados, esclarecendo que deverão ser realizados neste mesmo hospital.

Acuidade Visual: é uma medida da visão feita através da leitura de letras em uma tabela a uma determinada distância;

Biomicroscopia: é um exame da parte da frente dos olhos, com um aparelho composto por luzes e lentes;

Tonometria: é a medida da pressão dos olhos, feita com um pequeno aparelho, após a administração de 1 gota de anestésico tópico em cada olho;

Fundoscopia: é o exame da retina (parte interna do fundo do olho), feito através de uma luz e uma lente;

Perimetria Visual: é um exame que testa a visão através da apresentação de vários pontos luminosos dentro de uma cúpula, no qual o paciente aciona um botão do aparelho quando enxerga tais pontos.

Retinografia: é um exame dado por fotografias do fundo do olho após a aplicação de colírio que dilata a pupila. colírios.

OCT: é um exame dado por fotografias do fundo do olho sem a aplicação de

Exame de busca visual: exame onde o paciente permanece sentado a frente de uma tela de computador, onde aparecem números para você procurar com os olhos um determinado número (alvo). Os movimentos que o olho do paciente faz para achar o alvo na tela serão monitorados e gravados em vídeo porum sistema de computador, que tem uma câmera de vídeo acoplada que permanece filmando os olhos do paciente durante a 
busca dos alvos. Os dados do comportamento da busca visual, realizada pelo paciente, após filmagem, serão analisados e discutidos.

\section{Liberdade de Recusa e Garantia de Esclarecimentos e Sigilo}

Você será esclarecido(a) sobre a pesquisa em qualquer aspecto que desejar.

Você é livre para recusar-se a participar, retirar seu consentimento ou interromper a participação a qualquer momento. A sua participação é voluntária (não sendo obrigado a participar) e a recusa em participar não irá acarretar qualquer penalidade ou perda de benefícios, nem mesmo mudança no seu seguimento ou tratamento neste serviço.

Os pesquisadores irão tratar a sua identidade com padrões profissionais de sigilo. Os resultados serão demonstrados a você e permanecerão confidenciais. Seu nome ou o material que indique a sua participação não será liberado sem a sua permissão. Você não será identificado(a) em nenhuma publicação, texto, aula ou apresentação teórica que possa resultar deste estudo. Uma cópia deste consentimento informado será arquivada na Divisão de Oftalmologia (setor de glaucoma) do Hospital das Clínicas de Ribeirão Preto e outra será fornecida a você.

A sua participação nesta pesquisa é VOLUNTÁRIA e seu nome vai ficar em segredo (através de codificação numérica) e anonimato; não aparecerá nos resultados da pesquisa, não havendo, assim, possibilidade de ser identificado (mantendo total privacidade). Além disso, se for de sua vontade, nos comprometemos a prestar informações ou esclarecimentos atualizados durante todas as fases do estudo (inclusive dos seus resultados pessoais), mesmo que esses possam afetar a sua vontade de continuar participando. Caso concorde em participar, poderá também desistir em qualquer momento, sem qualquer prejuízo para o seu tratamento ou para o acompanhamento clínico durante e após a conclusão do trabalho.

Por acaso, se no decorrer do estudo for identificada alguma alteração nos exames oftalmológicos e/ou nos testes laboratoriais que forem feitos, você:

( ) Gostaria de ser comunicado

( ) Não gostaria de ser comunicado por um dos médicos responsáveis pelo projeto e que poderá me orientar sobre o significado dessas alterações e de quais providências deverão ser tomadas caso haja necessidade de tratamento, além de me encaminhar se necessário para um especialista e também prestar esclarecimentos sobre os possíveis riscos das alterações.

\section{DECLARAÇÃO DO PARTICIPANTE:}

$\mathrm{Eu}$, fui informado(a) dos objetivos da pesquisa acima de maneira clara e detalhada e tive todas minhas dúvidas esclarecidas. Sei que em qualquer momento poderei solicitar novas informações e modificar minha decisão se assim o desejar. A pesquisadora,Dra. Cássia Senger, certifica que todos os dados desta pesquisa serão estritamente confidenciais.

Em caso de dúvidas poderei contatar a equipe através do telefone (16) 3602-2499. Recebi uma cópia deste termo de consentimento livre e esclarecido e me foi dada a oportunidade de ler e esclarecer as minhas dúvidas.

Paciente e RG:

Ribeirão Preto, SP, de de 20 
9. Apêndice 
TABELA DE VALORES DE DADOS DOS PARTICIPANTES

\begin{tabular}{|c|c|c|c|c|c|c|c|c|c|c|c|}
\hline ID & G & $\mathrm{PIO}$ & $E / D$ & RNFL & MD & PSD & $\log M A R$ & IDADE & SEXO & TEMPO & IND \\
\hline 1 & C & 13 & 0,3 & 91 & $-2,910$ & 1,410 & 0 & 40 & $\mathrm{~F}$ & 113491 & 2,02 \\
\hline 2 & C & 12 & 0,3 & 107 & $-3,190$ & 2,030 & 0 & 78 & $\mathrm{~F}$ & 187664 & 3,03 \\
\hline 3 & $C$ & 13 & 0,5 & 105 & 1,240 & 1,290 & 0 & 53 & $\mathrm{~F}$ & 125604 & 1,72 \\
\hline 4 & C & 13 & 0,3 & 111 & $-0,700$ & 1,970 & 0 & 59 & $\mathrm{M}$ & 194298 & 3,42 \\
\hline 5 & C & 14 & 0,3 & 98 & $-0,830$ & 2,030 & 0,1 & 55 & $\mathrm{~F}$ & 139509 & 2,46 \\
\hline 6 & C & 15 & 0,4 & 103 & $-1,990$ & 1,090 & 0 & 46 & $\mathrm{~F}$ & 188729 & 3,09 \\
\hline 7 & C & 15 & 0,4 & 101 & 0,900 & 1,560 & 0 & 52 & M & 265474 & 5,37 \\
\hline 8 & $C$ & 15 & 0,3 & 111 & $-1,000$ & 1,340 & 0 & 55 & $\mathrm{~F}$ & 116267 & 2,11 \\
\hline 9 & C & 12 & 0,3 & 102 & $-0,670$ & 1,090 & 0,1 & 55 & $\mathrm{~F}$ & 175712 & 3,43 \\
\hline 10 & C & 10 & 0,4 & 103 & $-5,170$ & 2,780 & 0 & 51 & $\mathrm{M}$ & 111710 & 2,55 \\
\hline 11 & C & 13 & 0,3 & 113 & $-2,450$ & 1,870 & 0 & 41 & $\mathrm{~F}$ & 124583 & 2,25 \\
\hline 12 & C & 14 & 0,4 & 93 & $-1,760$ & 2,950 & 0,1 & 58 & $\mathrm{~F}$ & 98608 & 1,48 \\
\hline 13 & C & 12 & 0,3 & 95 & $-1,940$ & 2,260 & 0 & 59 & M & 144796 & 2,70 \\
\hline 14 & C & 14 & 0,3 & 95 & $-1,440$ & 1,620 & 0 & 55 & M & 158580 & 4,14 \\
\hline 15 & C & 14 & 0,3 & 116 & $-0,950$ & 1,560 & 0,1 & 49 & $\mathrm{~F}$ & 163714 & 3,60 \\
\hline 16 & C & 12 & 0,3 & 84 & $-2,110$ & 2,180 & 0 & 41 & $\mathrm{~F}$ & 136961 & 2,86 \\
\hline 17 & C & 18 & 0,4 & 100 & $-1,410$ & 1,190 & 0,2 & 73 & $\mathrm{~F}$ & 199227 & 3,66 \\
\hline 18 & C & 12 & 0,3 & 108 & 1,780 & 1,570 & 0,2 & 69 & $\mathrm{~F}$ & 630085 & 9,73 \\
\hline 19 & C & 15 & 0,3 & 98 & 0,210 & 1,540 & 0,1 & 64 & $\mathrm{~F}$ & 145703 & 2,68 \\
\hline 20 & C & 15 & 0,3 & 107 & $-3,010$ & 2,150 & 0,1 & 57 & $\mathrm{~F}$ & 195998 & 4,43 \\
\hline 21 & C & 15 & 0,4 & 116 & $-2,400$ & 2,670 & 0,2 & 72 & $\mathrm{~F}$ & 285886 & 4,42 \\
\hline 22 & C & 14 & 0,3 & 112 & $-1,550$ & 1,810 & 0 & 51 & $M$ & 126472 & 2,16 \\
\hline 23 & C & 16 & 0,3 & 99 & 0,220 & 1,750 & 0,1 & 57 & $M$ & 299456 & 5,10 \\
\hline 24 & C & 13 & 0,3 & 110 & $-2,910$ & 1,410 & 0 & 51 & $\mathrm{~F}$ & 105022 & 1,89 \\
\hline 25 & C & 13 & 0,3 & 85 & $-2,010$ & 2,000 & 0,1 & 80 & M & 199395 & 3,02 \\
\hline 26 & C & 16 & 0,3 & 114 & $-2,370$ & 2,630 & 0,1 & 58 & $\mathrm{~F}$ & 267364 & 4,96 \\
\hline 27 & C & 13 & 0,3 & 89 & $-1,720$ & 1,420 & 0 & 58 & $M$ & 196237 & 3,71 \\
\hline 28 & C & 12 & 12 & 104 & 0,070 & 1,540 & 0 & 41 & $\mathrm{~F}$ & 127782 & 1,95 \\
\hline 29 & $P$ & 16 & 0,8 & 61 & $-5,530$ & 6,800 & 0,2 & 76 & $\mathrm{~F}$ & 403148 & 7,66 \\
\hline 30 & $P$ & 15 & 0,9 & 62 & $-20,050$ & 6,020 & 0,3 & 78 & $\mathrm{~F}$ & 561278 & 9,34 \\
\hline 31 & $P$ & 17 & 0,7 & 88 & $-9,040$ & 10,320 & 0,0 & 57 & $M$ & 128170 & 2,51 \\
\hline 32 & $P$ & 12 & 0,9 & 56 & $-1,490$ & 2,120 & 0,0 & 40 & $M$ & 191051 & 3,47 \\
\hline 33 & $P$ & 16 & 0,9 & 77 & $-2,670$ & 2,670 & 0,0 & 63 & $M$ & 514734 & 8,77 \\
\hline 34 & $P$ & 22 & 0,7 & 95 & $-2,210$ & 1,450 & 0,0 & 43 & M & 176984 & 3,84 \\
\hline 35 & $P$ & 15 & 0,8 & 61 & $-23,640$ & 8,990 & 0,1 & 76 & $\mathrm{~F}$ & 273084 & 5,52 \\
\hline 36 & $P$ & 15 & 0,5 & 76 & $-3,070$ & 1,590 & 0,2 & 65 & $\mathrm{~F}$ & 231952 & 5,50 \\
\hline 37 & $P$ & 15 & 0,9 & 58 & $-17,440$ & 10,450 & 0,2 & 78 & $\mathrm{~F}$ & 816179 & 14,93 \\
\hline 38 & P & 8 & 0,9 & 59 & $-24,050$ & 10,470 & 0,1 & 68 & $\mathrm{~F}$ & 300622 & 6,37 \\
\hline 39 & $P$ & 15 & 0,4 & 87 & $-3,150$ & 1,800 & 0,0 & 65 & $M$ & 379162 & 6,52 \\
\hline $\begin{array}{l}40 \\
41\end{array}$ & $\begin{array}{l}\mathrm{P} \\
\mathrm{P}\end{array}$ & $\begin{array}{l}16 \\
14 \\
\end{array}$ & $\begin{array}{l}0,6 \\
0,8 \\
\end{array}$ & $\begin{array}{l}52 \\
81 \\
\end{array}$ & $\begin{array}{c}-16,080 \\
-2,510 \\
\end{array}$ & $\begin{array}{l}7,760 \\
2,370 \\
\end{array}$ & $\begin{array}{l}0,1 \\
0,0 \\
\end{array}$ & $\begin{array}{l}56 \\
65 \\
\end{array}$ & $\begin{array}{l}M \\
M\end{array}$ & $\begin{array}{l}202624 \\
175236 \\
\end{array}$ & $\begin{array}{l}3,98 \\
3,82 \\
\end{array}$ \\
\hline
\end{tabular}


conclusão

\begin{tabular}{cccccccccccc}
\hline ID & G & PIO & E/D & RNFL & MD & PSD & logMAR & IDADE & SEXO & TEMPO & IND \\
\hline 42 & $\mathrm{P}$ & 12 & 0,6 & 79 & $-3,660$ & 3,320 & 0,1 & 68 & $\mathrm{M}$ & 353094 & 7,16 \\
43 & $\mathrm{P}$ & 9 & 0,8 & 58 & $-5,410$ & 3,190 & 0,0 & 41 & $\mathrm{M}$ & 123889 & 2,70 \\
44 & $\mathrm{P}$ & 13 & 0,9 & 47 & $-27,100$ & 8,640 & 0,2 & 76 & $\mathrm{~F}$ & 794971 & 16,16 \\
45 & $\mathrm{P}$ & 20 & 0,9 & 51 & $-13,140$ & 5,970 & 0,1 & 54 & $\mathrm{~F}$ & 295054 & 7,34 \\
46 & $\mathrm{P}$ & 11 & 0,8 & 76 & $-13,770$ & 13,560 & 0,0 & 58 & $\mathrm{M}$ & 635152 & 9,35 \\
47 & $\mathrm{P}$ & 15 & 0,8 & 86 & $-6,190$ & 3,670 & 0,0 & 64 & $\mathrm{~F}$ & 514168 & 8,12 \\
48 & $\mathrm{P}$ & 16 & 0,9 & 62 & $-7,560$ & 6,060 & 0,2 & 70 & $\mathrm{~F}$ & 686730 & 15,78 \\
49 & $\mathrm{P}$ & 15 & 0,8 & 76 & $-6,920$ & 3,510 & 0,1 & 56 & $\mathrm{~F}$ & 214674 & 3,20 \\
50 & $\mathrm{P}$ & 14 & 0,5 & 89 & $-1,860$ & 2,370 & 0,1 & 58 & $\mathrm{~F}$ & 563710 & 10,16 \\
51 & $\mathrm{P}$ & 9 & 0,8 & 89 & $-1,670$ & 2,460 & 0,0 & 74 & $\mathrm{M}$ & 344140 & 5,04 \\
52 & $\mathrm{P}$ & 20 & 0,6 & 86 & $-3,520$ & 2,680 & 0,2 & 66 & $\mathrm{~F}$ & 560891 & 10,73 \\
53 & $\mathrm{P}$ & 19 & 0,8 & 71 & $-5,790$ & 3,070 & 0,1 & 74 & $\mathrm{~F}$ & 339017 & 6,49 \\
54 & $\mathrm{P}$ & 15 & 0,7 & 107 & 1,180 & 0,990 & 0 & 46 & $\mathrm{~F}$ & 99469 & 1,90 \\
55 & $\mathrm{P}$ & 16 & 0,9 & 61 & $-2,260$ & 2,090 & 0 & 53 & $\mathrm{M}$ & 220243 & 4,24 \\
56 & $\mathrm{P}$ & 20 & 0,6 & 94 & $-2,150$ & 1,750 & 0,1 & 50 & $\mathrm{M}$ & 213057 & 3,88 \\
57 & $\mathrm{P}$ & 12 & 0,8 & 74 & $-1,870$ & 1,430 & 0,0 & 52 & $\mathrm{~F}$ & 156813 & 3,15 \\
\hline
\end{tabular}

ID: identificador; G: Grupo ao qual o participante foi classificado; PIO: Pressão intra ocular em mmHg; E/D: razão escavação vertical/diâmetro disco óptico; RNFL: camada de fibras nervosas da retina em $\mu \mathrm{m}$; MD: valor do MD (mean deviation) da perimetria em dB; PSD: valor do PSD (pattern standart deviation) da perimetria em dB; logMAR: acuidade visual corrigida; TEMPO: tempo de exame de busca visual, em milissegundos; IND: tempo médio de busca visual para cada alvo individualmente, em segundos 